\title{
Alcoholemias, tráfico y otras tribulaciones constitucionales. Punto y aparte en "la Ley seca" de la Sanción administrativa
}

\author{
Ignacio Villaverde Menéndez \\ Profesor Titular Derecho Constitucional Universidad de Oviedo \\ ivillaverde@gijon.es \\ Belén Cuba Vila \\ Letrada Asesora Ayuntamiento de Gijón \\ bcuba@gijon.es
}

\begin{abstract}
Resumen
El presente artículo examina de manera pormenorizada la regulación vigente relativa a la sanción administrativa de la conducción bajo los efectos del alcohol, extendiéndose también a la conducta sancionable consistente en negarse a someterse a las pruebas de detección de alcohol. Este análisis se hace teniendo muy en cuenta la doctrina del Tribunal Constitucional sobre estos tipos administrativo y especialmente en su manifestación penal, y la de la Jurisdicción ordinaria en particular sobre el modo de proceder en la práctica de las pruebas de detección de alcohol. La tesis de este trabajo es que la reciente reforma legal de 2009 de la Ley de Seguridad Vial y antes en el año 2007 del Código Penal ha tratado de esclarecer y deslindar con un éxito y acierto relativos los ámbitos sancionadores administrativos y penal que hasta la fecha recaían sobre las mismas conductas (conducir bajo los efectos del alcohol y negarse a someterse a las pruebas etilométricas), y que tenían el efecto de reducir el expediente sancionador administrativo a una mera diligencia previa del procedimiento penal. El mantenimiento del tipo genérico de peligro en el Código Penal y la sanción a un tiempo administrativa y penal del delito de negativa a someterse a las etilometrías han frustado en buena medida la pretensión de que el Derecho Administrativo Sancionador adquiriese la autonomía y relevancia deseada con la reforma.
\end{abstract}

Palabras clave Seguridad vial, ingestión de alcohol, negativa a someterse a pruebas non bis in idem, alcoholemias, derecho administrativo sancionador.

\section{The new against the road safety: A simple of the criminal law administration}

\begin{abstract}
This article examines in a detailed way the in force regulation relative to the administrative sanction of the conduction under the effects of the alcohol, spreading also to the punishable conduct consisting of refusing to submit to the blood alcohol level test. This analysis is done bearing in mind very the doctrine of the Constitutional Court on these administrative types and especially in his penal manifestation, and that of the ordinary Jurisdiction especially on the way of proceeding in the practice of the blood alcohol level test. This thesis is that the recent legal reform of 2009 of the Road Security Law and before in 2007 of the Penal Code has tried to clarify and to define with a relative success and success the scopes administrative sanctioning and penal that until the date fell on the same conducts (to lead under the alcohol effects and to refuse to be put under blood alcohol level test), and that they had the effects to reduce the administrative sanctioning file to previous diligence of the penal procedure. The maintenance of the generic type of danger in the Penal Code and the administrative and at the same time penal sanction of the refusal crime to be put under blood level test they have frustrated the pretension that the Sanctioning Administrative Law acquired the anatomy and relevance wished with the reform.
\end{abstract}




\section{CONSIDERACIONES INICIALES, O POR QUÉ LLAMAMOS “ADMINISTRATIVO” A LO QUE HEMOS CONVERTIDO EN “PENAL”}

A nadie se le oculta que uno de los asuntos que ha dado lugar a un número nada desdeñable de Sentencias y Autos del Tribunal Constitucional (en adelante, TC) en el trámite de amparo es justo el relativo a lo que, para abreviar, se denominará en este opúsculo "alcoholemias"; esto es, la imposición de sanciones administrativas o penales por conducir bajo los efectos de la ingesta de bebidas alcohólicas. Lo que no ha de extrañar, ya que probablemente sea el ámbito en el que de forma más evidente se ha puesto de manifiesto la intersección de la disciplina sancionadora administrativa con la penal, lo que ha sido causa indubitada de fricciones entre ambos sistemas y alguna que otra disfunción sustantiva y procesal de la que trataremos de dar cumplida cuenta en las páginas que siguen'. Prueba probablemente de esa disolución del Derecho Administrativo sancionador en el Penal acaso resulte ser que la doctrina del TC sobre las alcoholemias se haya forjado fundamentalmente al resolver los amparos promovidos contra las condenas penales que le han permitido descender al ámbito previo Administrativo.

Probablemente en esa confusión permanente entre lo administrativo y lo penal, azuzada por la relevancia social del tráfico, es lo que puede explicar la cascada de reformas y contrarreformas legales en esta materia. Prescindiendo de antecedentes más remotos, de entre las últimas y más significativos al propósito de estas líneas cabe citar la Ley Orgánica 15/2007, de 30 de noviembre, por la que se modifica la Ley Orgánica 10/1995, de 23 de noviembre, del Código Penal (en adelante, CP) en materia de seguridad vial, dando nueva redacción al artículo 379 CP e incorporando el siguiente tipo:

“2. Con las mismas penas (prisión de tres a seis meses o a la de multa de seis a doce meses y trabajos en beneficio de la comunidad de treinta y uno a noventa días, y, en cualquier caso, a la de privación del derecho a conducir vehículos a motor y ciclomotores por tiempo superior a uno y hasta cuatro años) será castigado el que condujere un vehículo de motor o ciclomotor bajo la influencia de drogas tóxicas, estupefacientes, sustancias psicotrópicas o de bebidas alcohólicas. En todo caso será condenado con dichas penas el que condujere con una tasa de alcohol en aire espirado superior a 0,60 miligramos por litro o con una tasa de alcohol en sangre superior a 1,2 gramos por litro".

Que se complementa con la cláusula general establecida en el artículo $380 \mathrm{CP}$, cuya redacción también fue dada por la citada reforma de 2007:

“1. El que condujere un vehículo a motor o un ciclomotor con temeridad manifiesta y pusiere en concreto peligro la vida o la integridad de las personas será castigado con las penas de prisión de seis meses a dos años y privación del derecho a conducir vehículos a motor y ciclomotores por tiempo superior a uno y hasta seis años.

1 Consúltese el trabajo de Valencia Martín, G. (2000), en especial pp. 177 y ss; y Nieto, A. (2002), pp. 148 y ss. Con carácter general véase también el de Miguel Casino (2008). 
2. A los efectos del presente precepto se reputará manifiestamente temeraria la conducción en la que concurrieren las circunstancias previstas en el apartado primero y en el inciso segundo del apartado segundo del artículo anterior"2

\section{Y el artículo 383:}

"El conductor que, requerido por un agente de la autoridad, se negare a someterse a las pruebas legalmente establecidas para la comprobación de las tasas de alcoholemia y la presencia de las drogas tóxicas, estupefacientes y sustancias psicotrópicas a que se refieren los artículos anteriores, será castigado con la penas de prisión de seis meses a un año y privación del derecho a conducir vehículos a motor y ciclomotores por tiempo superior a uno y hasta cuatro años".

La Ley Orgánica 15/2007, de 30 de noviembre, también reformó el Real Decreto Legislativo 339/1990 de 2 de marzo, por el que se aprueba el texto articulado de la Ley sobre Tráfico, Circulación de vehículos a motor y Seguridad Vial (en adelante, LSV); que a su vez ha sido recientemente modificada por Ley 18/2009, de 23 de noviembre, fundamentalmente en cuanto al procedimiento sancionador, conservando no obstante en su artículo 65.5.c) y d) como infracción muy grave las conductas que se van a analizar en este trabajo, y que entrarán en vigor en su nueva expresión a partir de mayo de 2010 (y que deben leerse a la luz de su desarrollo reglamentario en el Capítulo IV del Reglamento General de Circulación aprobado por Real Decreto 1428/2003, de 21 noviembre (en adelante, RLSV)3:

2 Sin que quepa olvidar lo dispuesto en el artículo $381 \mathrm{CP}$, cuya literalidad también es fruto de la reforma de 2007: “1. Será castigado con las penas de prisión de dos a cinco años, multa de doce a veinticuatro meses y privación del derecho a conducir vehículos a motor y ciclomotores durante un período de seis a diez años el que, con manifiesto desprecio por la vida de los demás, realizare la conducta descrita en el artículo anterior. 2. Cuando no se hubiere puesto en concreto peligro la vida o la integridad de las personas, las penas serán de prisión de uno a dos años, multa de seis a doce meses y privación del derecho a conducir vehículos a motor y ciclomotores por el tiempo previsto en el párrafo anterior".

3 Artículo 20: No podrán circular por las vías objeto de la legislación sobre tráfico, circulación de vehículos a motor y seguridad vial los conductores de vehículos ni los conductores de bicicletas con una tasa de alcohol en sangre superior a 0,5 gramos por litro, o de alcohol en aire espirado superior a 0,25 miligramos por litro. Cuando se trate de vehículos destinados al transporte de mercancías con una masa máxima autorizada superior a 3.500 kilogramos, vehículos destinados al transporte de viajeros de más de nueve plazas, o de servicio público, al transporte escolar y de menores, al de mercancías peligrosas o de servicio de urgencia o transportes especiales, los conductores no podrán hacerlo con una tasa de alcohol en sangre superior a 0,3 gramos por litro, o de alcohol en aire espirado superior a 0,15 miligramos por litro. Los conductores de cualquier vehículo no podrán superar la tasa de alcohol en sangre de 0,3 gramos por litro ni de alcohol en aire espirado de 0,15 miligramos por litro durante los dos años siguientes a la obtención del permiso o licencia que les habilita para conducir. A estos efectos, sólo se computará la antigüedad de la licencia de conducción cuando se trate de la conducción de vehículos para los que sea suficiente dicha licencia (negrita de los autores). Artículo 21: Todos los conductores de vehículos y de bicicletas quedan obligados a someterse a las pruebas que se establezcan para la detección de las posibles intoxicaciones por alcohol. Igualmente quedan obligados los demás usuarios de la vía cuando se hallen implicados en algún accidente de circulación (artículo 12.2, párrafo primero, del Texto Articulado). Los agentes de la autoridad encargados de la vigilancia del tráfico podrán someter a dichas pruebas: a) A cualquier usuario de la vía o conductor de vehículo implicado directamente como posible responsable en un accidente de circulación. b) A quienes conduzcan cualquier vehículo con síntomas evidentes, manifestaciones que denoten o hechos que permitan razonablemente presumir que lo hacen bajo la influencia de bebidas alcohólicas. c) A los conductores 
“5. Son infracciones muy graves, cuando no sean constitutivas de delito, las siguientes conductas:

c) La conducción por las vías objeto de esta Ley habiendo ingerido bebidas alcohólicas con tasas superiores a las que reglamentariamente se establezcan, y en todo caso, la conducción bajo los efectos de estupefacientes, psicotrópicos, estimulantes y cualquier otra sustancia de efectos análogos.

d) Incumplir la obligación de todos los conductores de vehículos de someterse a las pruebas que se establezcan para la detección de posibles intoxicaciones de alcohol, estupefacientes, psicotrópicos, estimulantes y otras sustancias análogas, y la de los demás usuarios de la vía cuando se hallen implicados en algún accidente de circulación".

Probablemente sea en esta materia en la que el Derecho Administrativo sancionador ha sucumbido de forma más evidente al efecto de atracción inexorable que en estos tiempos tiene el Penal, que le ha impuesto sus exigencias hasta el punto de que los controles de alcoholemia realizados por las Fuerzas y Cuerpos de Seguridad, si provocan un expediente administrativo sancionador por infracción del citado artículo 65.5 c) o d) LSV, acaban siendo más un acto preparatorio, casi una diligencia previa penal, antesala de la instrucción de la causa criminal pertinente por comisión del delito tipificado en el artículo 379.2 CP, y que hoy ya es propiamente, como antes lo era el tipo administrativo, un delito de conducción bajo los efectos del alcohol y no solo un delito de riesgo. Ese perfecto solapamiento de conductas sancionables alcanza el paroxismo en el caso de la infracción consistente en negarse a someterse a las pruebas de detección de alcohol cuya definición en la LSV y el CP es tan pareja que resultan de difícil (a los autores de este trabajo les resulta de imposible) deslinde ${ }^{4}$. El expediente administrativo sancionador de una alcoholemia, por una u otra vía (artículos 379.2 ó $383 \mathrm{CP}$ ), terminaba por ser en la mayoría de los casos una simple prueba preconstituida y anticipada, una prueba sumarial, del juicio penal.

Que así es provoca serios desajustes sistémicos en el ius puniendi del Estado como es la irresoluble cuestión del non bis in idem cuando unos mismos hechos se sancionan por el Derecho Administrativo y por el Derecho Penal5; o la difícil traslación al ámbito sancionador administrativo de las garantías procesales-penales del artículo 24 CE, con resultados, cuando menos, desconcertantes, y que terminan por convertir a los tribunales contencioso-administrativos en un remedio involuntario de jurisdicción penal.

A nuestro juicio el origen de esta desconcertante confusión debe buscarse en una jurisprudencia del TC que, volvemos a repetir que a nuestro modesto entender, a equivo-

que sean denunciados por la comisión de alguna de las infracciones a las normas contenidas en este Reglamento. d) A los que, con ocasión de conducir un vehículo, sean requeridos al efecto por la autoridad o sus agentes dentro de los programas de controles preventivos de alcoholemia ordenados por dicha autoridad.

4 Sobre las dudas de constitucionalidad de esta reforma, consúltese Cuenca Sánchez, J. C. (2007), pp. 1502-1506; véase también Sarrato Martínez, L. (2009).

5 Sobre esta prolija cuestión véase por todos Pérez Manzano, M. (2003). 
cado las fuentes de las garantías constitucionales del ius puniendi según se trate de su expresión administrativa o penal. No cabe duda de que los principios constitucionales de la legalidad sancionadora del artículo 25 CE son de aplicación severa a cualquier expresión del ius puniendi, sea el administrativo, sea el penal. Sin embargo, otra cosa sucede con el artículo 24.2 CE. Precepto encuadrado, quiérase o no, en las garantías procesales en el ámbito del ejercicio de la jurisdicción, y no del actuar de la Administración Pública; esto es, que el artículo 24 CE está para poner orden y reglas al proceso judicial, y en lo que ahora interesa, al penal, pero no al proceso administrativo. Las garantías constitucionales de la presunción de inocencia, a no autoincriminarse, a no declarar contra uno mismo y a ser informado de la acusación, en lo que ahora interesa, lo son del proceso penal, no del proceso administrativo sancionador. A éste lo que cabe exigirle son los principios que resultan de lo dispuesto en el artículo 9.3 CE; a saber, legalidad, publicidad, irretroactividad, seguridad jurídica e interdicción de la arbitrariedad. Puede que la recta aplicación de estos principios puedan llevar a consecuencias y garantías parejas e incluso similares a las que el citado artículo 24.2 CE impone al proceso penal; pero el edificio del poder sancionador de la Administración se levantará sobre pilares distintos, y acaso deba ser así porque ese edificio persigue fines y se articula de manera distinta al penal.

Tratando de ser breves, el Derecho administrativo sancionador expresa, en términos generales, la reacción del ordenamiento jurídico frente al incumplimiento de las normas relativas a las conductas individuales o colectivas publificadas; esto es, intervenidas por el Derecho Público creando respecto de ellas una vinculación positiva de la persona en su observancia. Qué bien distinta es esta manera de articular la sanción jurídica frente a las conductas publificadas, a la que el propio ordenamiento arbitra para aquellas otras previstas para el incumplimiento de las normas que regulan los términos y alcance, por el contrario, de la vinculación negativa del ciudadano a ese mismo ordenamiento, en fin, el Derecho Privado, que sólo puede ser la arbitrada a través del proceso judicial civil. Repárese en otro importante aspecto, y es que, además, el cauce penal está reservado (o debiera estarlo) a aquellas conductas, intervenidas o no, cuya gravedad es tal que ponen en grave riesgo o lesionan bienes, intereses o derechos constitucionales, y no otros. La sanción administrativa persigue un fin más modesto, asegurar la observancia rigurosa de las normas que fijan la única conducta individual legalmente admisible, que es la fijada en la norma que interviene u publifica su conducta. La sanción administrativa persigue el sometimiento pleno a esas normas, la penal lo hace del castigo de quien daña bienes constitucionales.

Si hay un terreno donde este deslinde sistémico se volatilizaba en las alcoholemias, y muy en especial en el tipo de desobediencia a la orden de someterse a la prueba etilométrica. Incluso la modificación del CP de 2007 y la actual reforma de la LSV, que parecía haber puesto punto y aparte en esta historia en la que la alcoholemia en vía administrativa terminaba por reducirse a una diligencia previa en el proceso penal, finalmente marra el propósito porque las cosas terminan por seguir igual al conservar el CP los tipos genéricos y abstractos que ya existían respecto de la conducción bajo los efectos del alcohol. Pues bien, en la alcoholemia, éstos y muchos otros asuntos más salen a la luz. A alguno de ellos dedicaremos unas líneas. 


\section{APUNTE DE UNA HISTORIA CONSTITUCIONAL DE LAS ALCOHOLEMIAS}

Acaso convenga, antes de seguir camino, detenernos un instante, siquiera breve, sobre el devenir que tuvieron las alcoholemias en la jurisprudencia del TC6.

La historia constitucional de las alcoholemias está ligada a la temprana doctrina del TC relativa a la validez jurídica de las pruebas preconstituidas, anticipadas o sumariales. Superados alguno titubeos, las pruebas de detección y medición de alcohol en sangre practicadas por los Agentes de la Autoridad fueron consideradas pericias que se allegaban a los procedimientos sancionadores, penal o administrativo, de dos formas: como prueba testifical mediante la ratificación del atestado por los Agentes que hubieran intervenido personalmente en su práctica, y como pericias técnicas incorporadas a documentos que podían incorporarse, bajo ciertas condiciones, al proceso como verdaderas pruebas de cargo (etilometría, análisis de sangre en su caso, test para la descripción y comprobación de signos externos, etc.) ${ }^{7}$. Esta doctrina general dio lugar a un largo elenco de cuestiones particulares que debieron ser dilucidadas por el TC en sus resoluciones ${ }^{8}$.

Resuelta la cuita relativa a la prueba de cargo fundamentalmente en los procesos penales, y trasladable sus criterios a los expedientes sancionadores administrativos mutatis mutandis, el TC abordó el aquilatamiento de la doctrina relativa a la inexistencia de vulneración del principio non bis in idem cuando los mismos hechos (conducción bajo los efectos del alcohol) eran sancionados sucesivamente en la vía administrativa (por superar una determinada tasa de alcohol en sangre) y luego en la penal (por un delito contra el tráfico y la seguridad vial de peligro abstracto); y muy particularmente, sobre la necesidad en la vía penal de acreditar, junto con la superación del límite fijado por la tasa administrativamente de alcohol en sangre, otros hechos que viniesen a corroborar que, además de conducir bajo los efectos del alcohol, se creaba, justo por ello, una situación objetiva y real de peligro para el resto de usuarios de la vía y los peatones.

La última doctrina del TC en esta primera fase (larga fase) de la jurisprudencia constitucional se ciñó a determinar en qué casos la condena penal por infracción del artículo 379 CP 1995 (antes, el artículo 340 bis a) del CP de 1973) se asentaba en prue-

6 Véanse los siguientes trabajos, Lorente Hurtado, F. (1986), pp. 59-70; Serrano Hoyo, G. (1993); y Díaz Revorio, F. J. (2000), pp. 121-168.

7 La primera resolución del TC que se ocupó en efecto de una alcoholemia fue el ATC 62/1983. En él se formula por primera vez la cuestión relativa al valor probatorio de las etilometrías en los procesos penales.

8 Desde la fiabilidad de los etilómetros, el valor de los test y los formularios que cubrían los Agentes para su práctica, como prueba documental de cargo, la necesidad de que testificasen y ratificasen los resultados de las pruebas etilométricas (SSTC 145/1987, 22/19888, 5/1989, 222/1991, 2/2003 por citar la más reciente), o la posibilidad de que fuese prueba de cargo únicamente la medición etilométrica y/o los signos externos que corroborasen la conducción bajo los efectos del alcohol u otras sustancias psicotrópicas, 186 torios constituía una detención del artículo 17,3 CE (STC 107/1985), etc. 
bas de cargo que no sólo acreditaban la conducción bajo los efectos del alcohol (u otras sustancias), sino también la generación de un peligro cierto para las personas (con la correspondiente gradación en la que podría trazarse una regla en donde en proporción inversa se cruzaban dos valores: la tasa de alcohol en sangre, y la necesidad de prueba de otras circunstancias concurrentes, de manera que, a más tasa de alcohol, menos necesidad de prueba concurrente, pues de esa tasa se infería sin solución de continuidad la peligrosidad de la conducta penada).

Consolidada la doctrina constitucional sobre la prueba de cargo de las alcoholemias, y deslindado (o al menos, ese fue el propósito) el ámbito de la sanción administrativa, del de la penal, vino la duda sobre la constitucionalidad del delito de negarse a someterse a las pruebas, que fue despejada sancionando la adecuación constitucional de dicha norma en la STC 161/1997, reiterada en la 234/1997.

Tras este largo devenir, las cuestiones constitucionales relativas a la alcoholemia terminaron por reducirse a en qué casos y con arreglo a qué criterios se podía dar el salto de la mera sanción administrativa por superar el límite reglamentario de alcohol en sangre, a la sanción penal por el peligro creado como consecuencia de la superación de esos límites. Pues bien, la reforma del CP de 2007 arriba aludida ha despejado el misterio de esta cábala porque el legislador penal ha querido que su reproche venga seguido del administrativo de manera que hasta una tasa de alcohol en sangre la sanción es administrativa, y a partir de esa tasa la sanción será penal. Conservando no obstante el tipo penal genérico de la conducción peligrosa como consecuencia del consumo de alcohol u otras sustancias.

\section{LOS HITOS DE LA JURISPRUDENCIA CONSTITUCIONAL}

La historia de la alcoholemia en el seno de la jurisprudencia constitucional, como ya se ha dicho, es ciertamente antigua. Casi cabe decir que acompaña al TC desde su puesta en marcha. Pero sin duda, hay cuatro hitos claros en esta historia: las SSTC 107/1985, la 161/1997, la 111/1999, la 188/2002 y la 2/2003.

La STC 107/1985 aborda la cuestión desde la perspectiva de las retenciones de los conductores practicadas en los controles de alcoholemia. En esa ocasión, el recurrente sostuvo que dichas retenciones eran "detenciones gubernativas" sujetas a las reglas del apartado 3 del artículo 17 CE, so pena, de ser así, de ser tenidas por detenciones ilegales contrarias al citado precepto constitucional. Pero, además, esa misma

9 No deben perderse de vista las Sentencias dictadas por el TS relativas a la aplicación del delito de negativa a someterse a las pruebas de detección de alcohol, en particular las Sentencias de 9 de diciembre de 1999 y la de 22 de marzo de 2002, que han sido objeto de estos comentarios, Cuesta Pastor, J. L. (2000), Marín de Espinosa Ceballos, E. B. (2000), Varona Gómez, D. (2000), Martínez Ruiz, J. (2002), Miró Llinares, F. (2002) y (2003). 
Sentencia aborda una serie de extremos capitales en orden a definir la conformidad constitucional de las alcoholemias: su naturaleza, el sometimiento a ellas como expresión de la sujeción general a la potestad de policía, la no afectación del derecho a no autoincriminarse o la relevancia constitucional de la ausencia de previa información al ciudadano sobre sus derechos al momento de someterse por iniciativa propia a un control preventivo de alcoholemia.

\section{Así rezaba su FJ 3.:}

"Para nuestro análisis hemos de partir de la consideración de que los derechos declarados en el art. 17.3 de la norma fundamental corresponden al 'detenido', esto es, a quien ha a sido privado provisionalmente de su libertad por razón de la presunta comisión de un ilícito penal y para su puesta a disposición de la autoridad judicial en el plazo máximo de setenta y dos horas, de no haber cesado antes la detención misma, según prescribe el núm 2. del mismo artículo. Las garantías exigidas por el art. 17.3 -información al detenido de sus derechos y de las razones de su detención, inexistencia de cualquier obligación de declarar y asistencia letrada- hallan, pues, su sentido en asegurar la situación de quien, privado de su libertad, se encuentra ante la eventualidad de quedar sometido a un procedimiento penal, procurando así la norma constitucional que aquella situación de sujeción no devenga en ningún caso en productora de la indefensión del afectado. No es esta situación, sin embargo, la de quien, conduciendo un vehículo de motor, es requerido policialmente para la verificación de una prueba orientativa de alcoholemia, porque ni el así requerido queda, sólo por ello, detenido en el sentido constitucional del concepto, ni la realización misma del análisis entraña exigencia alguna de declaración autoincriminatoria del afectado, y sí sólo la verificación de una pericia técnica de resultado incierto y que no exorbita, en sí, las funciones propias de quienes tienen como deber la preservación de la seguridad del tránsito y, en su caso, en mérito de lo dispuesto en el art. 492, $1^{\circ}$ de la L.E.Cr., la detención de quien intentare cometer un delito o lo estuviere cometiendo. En estos términos, la verificación de la prueba que se considera supone, para el afectado, un sometimiento, no ilegítimo desde la perspectiva constitucional, a las normas de policía, sometimiento al que, incluso, puede verse obligado sin la previa existencia de indicios de infracción, en el curso de controles preventivos realizados por los encargados de velar por la regularidad y seguridad del tránsito (art. 1 in fine de la Orden de 29 de julio de 1981). La realización de esta prueba, por lo tanto, así como la comprobación de otro modo por agentes del orden público de la identidad y estado de los conductores, no requiere de las garantías inscritas en el art. 17.3 de la Norma fundamental, dispuestas específicamente en protección del detenido y no de quienquiera que se halle sujeto a las normas de la policía de tráfico" (cursiva de los autores).

"Lo anterior nos lleva, así, a concluir que no se produjo en este caso vulneración alguna de los derechos del recurrente recogidos en el art. 17.3 con ocasión de la realización de las pruebas de alcoholemia llevadas posteriormente al proceso penal. La verificación misma de las pruebas -único aspecto a considerar aquí, por su incidencia ulterior en la condena penal- no configura el supuesto de "detención" contemplado en aquel precepto constitucional ni ha de rodearse, por ello, de unas garantías llamadas a tutelar una situación bien distinta y que, por lo demás, resulta- 
rían de satisfacción harto difícil en un caso como el que se considera. Tampoco ostentaba derecho fundamental alguno el hoy demandante, como se le hizo saber en la Sentencia dictada en apelación, a que se le indicara expresamente por los agentes el fin al que se encaminaba la práctica de la prueba, alegato este que parece basarse en un inexistente derecho a la ignorancia del ordenamiento. $Y$ es igualmente irrelevante, de otra parte, lo aducido en orden a cómo no fue informado previamente el actor de su derecho a no someterse a las pruebas controvertidas. Sin perjuicio de que, según consta en autos, el demandante no se negó a la realización de la pericia, es lo cierto que la advertencia así reclamada carece de todo fundamento normativo, debiendo someterse al examen en cuestión el requerido para ello, y sin perjuicio, porque la cuestión es ya diferente, de que nadie pueda ser coercitivamente compelido, con vis física, a la verificación de este tipo de análisis. En relación con todo ello conviene recordar también que no se debe a la imposición policial, sino a la propia iniciativa del hoy recurrente, la decisión de abandonar el lugar de los hechos para someterse a una nueva prueba con el alcoholómetro de precisión, supuesto radicalmente distinto a aquel que dio lugar a la decisión de la Comisión Europea de Derechos Humanos de 13 de diciembre de 1979, que la representación del recurrente atribuye, sin duda por error, al Tribunal Europeo de Derechos Humanos y en la que, por lo demás, se sostiene que si bien la ejecución forzosa de un análisis de sangre constituye una privación de libertad, esta privación es, en el caso considerado, legítima y no contraria al art. 5 de la Convención".

"Sólo, en definitiva, a partir de la apreciación del resultado positivo del examen pericial practicado puede hablarse, en rigor, de detención del demandante, porque sólo entonces hubo ya indicios de la posible consumación por el mismo del tipo descrito en el núm $1 .^{\circ}$ del art. 340 bis, a), del Código Penal. La regularidad de la detención desde aquel momento es cuestión ya ajena al presente proceso, que puede, así, resolverse constatando que la obtención policial de la prueba no fue antijurídica y que, por lo mismo, no quedó viciado, al considerarla, el enjuiciamiento penal al que fue sometido el demandante" (cursiva de los autores)

La cita es extensa, pero de gran importancia también para las condiciones de constitucionalidad de los expedientes administrativos instruidos con ocasión de las pruebas de alcoholemia. En efecto, de este FJ $3 .^{\circ}$ se infiere con claridad que la realización de controles de alcoholemia por los agentes de la autoridad y el sometimiento de los conductores a ellos no activa las garantías del artículo 17.3 CE, por cuanto no se tratan de detenciones en el seno de unas diligencias penales, sino de meras retenciones temporales de naturaleza estrictamente administrativa, sustentadas en las potestades de policía a la que los ciudadanos están sujetos, so pena de ser sancionados en el caso de no hacerlo (sanción o en su caso delito de desobediencia a la autoridad).

El siguiente hito es el alcanzado con la STC 111/1999. En esta Sentencia el recurrente suscitó frontalmente las cuestiones esenciales de la materia: la imposibilidad de que los controles de alcoholemia puedan considerarse pruebas de cargo si no se practican con todas las garantías, y de que pueda tenerse el resultado de esos controles como si de una prueba tasada se tratase (en el caso de autos, ambas cuestiones se ligan al proceso penal en el que fue condenado el recurrente; pero las reflexiones del TC bien sirven, como se verá, al objeto de este artículo). 
En esta Sentencia, el recurrente vino en plantear sin saberlo la cuestión relativa a las pruebas de cargo fundadas en presunciones ${ }^{10}$. En efecto, su queja consiste en que los resultados de las etilometrías son elevadas a la categoría de presunción iuris et de iure sobre la comisión del delito tipificado en el artículo 340 bis a) CP 1973, y hoy en el vigente 379 CP 1995 (lo que en la demanda de amparo denomina el actor, prueba “tasada”). El propio TC así lo dice en su FJ 3.:

"No corresponde a este Tribunal interpretar las normas penales. Pero comoquiera que se califique a este tipo delictivo, bien de peligro simplemente bien de peligro abstracto o remoto, en ningún caso el derecho a la presunción de inocencia tolera que alguno de los elementos constitutivos del delito se presuma en contra del acusado, sea con una presunción iuris tantum sea con una presunción iuris et de iure. La primera modalidad de presunción iuris tantum no es admisible constitucionalmente ya que, como declaró la STC 105/1988, produce una traslacióno inversión de la carga de la prueba, de suerte que la destrucción o desvirtuación de tal presunción corresponde al acusado a través del descargo, lo que no resulta conciliable con el art. 24.2 C.E. Y la segunda modalidad, la presunción iuris et de iure, tampoco es lícita en el ámbito penal desde la perspectiva constitucional, puesto que prohíbe la prueba en contrario de lo presumido, con los efectos, por un lado, de descargar de la prueba a quien acusa y, por otro, de impedir probar la tesis opuesta a quien se defiende, si es que opta por la posibilidad de probar su inocencia, efectos ambos que vulneran el derecho fundamental a la presunción de inocencia. Ahora bien, como es lógico lo anterior no obsta a la legitimidad constitucional de la prueba de indicios, puesto que ésta versa sobre los hechos y no directamente sobre los elementos constitutivos del delito, y siempre que reúna los requisitos y condiciones que hemos exigido reiteradas veces (como más reciente, STC 220/1998)" (cursiva de los autores).

Esta importante Sentencia reitera la ya asentada doctrina del TC sobre los términos en los que las pruebas etilométricas pueden ser allegadas, en este caso, al proceso penal (aunque, como venimos diciendo, con los matices debidos, bien valen para el expediente administrativo). Así se expresaba en su FJ 5.:

“Otra de las quejas formuladas en la demanda destaca la falta de garantías de los controles de alcoholemia practicados al recurrente tras la colisión. Por lo que resulta necesario exponer la doctrina constitucional que hemos reiterado en otras ocasiones acerca de las garantías que deben rodear a tales controles cuando se utilicen los resultados de los mismos como prueba de cargo y comenzar recordando que el control de alcoholemia constituye una pericia técnica de resultado incierto (SSTC 107/1985, 252/1994, 173/1997, 161/1997, 234/1997) y al que puede atribuirse el carácter de prueba pericial lato sensu (SSTC 145/1985, 89/1988, 173/1997). Normalmente está incluido en el atestado policial y, por lo tanto, tiene el valor de denuncia (SSTC 145/1985, 22/1988); si bien no cabe su reproducción en el juicio oral,

10 Sobre el valor de las presunciones como pruebas en el Derecho Administrativo Sancionador véanse los dos imprescindibles trabajos de Casino Rubio 1(2010) y en especial 2(2010, y su relación con la prueba por indicios y la carga probatoria en p. 214 y ss). 
puede llegar a producir los efectos de una prueba preconstituida (SSTC 138/1992, 173/1997). A este respecto, está supeditado constitucionalmente a la observancia de determinadas exigencias precisadas por constante doctrina de este Tribunal (SSTC 145/1985, 148/1985, 145/1987, 22/1988, 89/1988, 5/1989, 3/1990, 222/1991, 24/1992)".

“En primer lugar, es necesario que en su práctica se cumplan las garantías formales establecidas al objeto de preservar el derecho de defensa en condiciones similares a las que se ofrecen dentro del proceso judicial, especialmente, el conocimiento del interesado a través de la oportuna información de su derecho a un segundo examen alcoholimétrico y a la práctica médica de un análisis de sangre. En segundo lugar, es preciso que la incorporación al proceso se realice de forma que resulten respetados, en la medida de lo posible, los principios de inmediación judicial, oralidad y contradicción. En último término, no puede ser bastante para desvirtuar la presunción de inocencia la simple lectura o reproducción en el juicio oral del atestado en el que conste el dato objetivo del correspondiente control practicado, si no hay además oportunidad para el Juzgador de examinar por sí mismo la realidad de las circunstancias que determinaron su práctica, singularmente a través de la ratificación y declaración complementaria de quienes la efectuaron o de otros elementos probatorios concernientes a la conducción realizada, y para el mismo acusado de rebatir en el cauce procesal la versión de la acusación sobre tales extremos. En relación con este último punto de la ratificación del resultado del control de alcoholemia, la STC 24/1992 resumió las posibilidades de tal ratificación, indicando que, además de que se produzca por los Agentes que verificaron el control, puede tener lugar por otros testigos (SSTC 100/1985, 145/1987; AATC 797/1985, 1.421/1987, 191/1988), por el resultado obtenido con un control de extracción de sangre (ATC 304/1985), por la declaración del perjudicado (ATC 305/1985), por las propias circunstancias que rodearon la conducción (ATC 649/1985) y por la propia declaración del acusado (SSTC 145/1987, 89/1988; AATC 62/1983, 1.079/1987)" (cursiva de los autores).

Parece claro que, siendo el proceso penal más exigente en garantías constitucionales que el administrativo, lo dicho por el TC podría aplicarse, mutatis mutandis, para el pertinente expediente administrativo. Pero la Sentencia sigue:

"En el supuesto de hecho que nos ocupa, el recurrente objeta que los Agentes de Policía que le efectuaron tres controles de alcoholemia mediante la técnica de verificación del aire espirado a través de etilómetros -dos en el lugar del accidente y un tercero en las dependencias de la Policía Local-, no le ofrecieron la posibilidad de contrastar los resultados positivos de la tasa de alcohol a través de un análisis de sangre efectuado por personal facultativo. Ciertamente, el art. 12.2 de la Ley sobre Tráfico, Circulación de Vehículos a Motor y Seguridad Vial (aprobada por el Real Decreto Legislativo 339/1990, de 2 de marzo) dispone en su párrafo segundo que a petición del interesado o por orden de la Autoridad judicial se podrán repetir las pruebas a efectos de contraste, pudiendo consistir en análisis de sangre, orina u otros análogos. Y el Reglamento General de Circulación (aprobado por Real Decreto 13/1992, de 17 de enero) establece en el art. 23.3 que el Agente ha de informar al interesado del derecho que tiene a formular cuantas alegaciones u observaciones tenga por conveniente, las cuales se han de consignar por diligencia, y asimismo ha 
de informarle del derecho a contrastar los resultados obtenidos mediante análisis de sangre, orina u otros análogos; en tanto que el art. 24.2 del mismo Reglamento dispone que si el resultado de la segunda prueba fuera positivo, el Agente ha de consignar las advertencias hechas al interesado, especialmente la del derecho que le asiste a contrastar los resultados obtenidos en las pruebas de detección alcohólica por el aire espirado mediante análisis adecuados, acreditándose en las diligencias las pruebas o análisis practicados en el centro sanitario al que fue trasladado el interesado".

"Entre las actuaciones no consta la diligencia escrita de ofrecimiento al recurrente del análisis de sangre, tal y como se exige reglamentariamente, por lo que tal omisión es imputable a los Agentes. Las garantías que rodean a los controles de alcoholemia en el momento de su práctica van dirigidas a garantizar la contradicción y a que no exista indefensión por parte del sometido a los mismos, todo ello con vistas a que eventualmente dichos controles puedan operar en su día como pruebas preconstituidas si son debidamente ratificadas en el juicio oral. Sin embargo, en el presente caso concurren otras circunstancias particulares dignas de mención" (cursiva de los autores).

La STC 188/2002 establece los criterios constitucionales de la validez y calidad constitucional de las pruebas de cargo consistentes en las testificales de los Agentes actuantes, el valor del atestado, las mediciones, planos, croquis y demás, y en qué casos la mera lectura del atestado no es suficiente como prueba. En síntesis, son pruebas de cargo suficiente en la vía penal las testificales de los agentes que presenciaron los hechos y redactaron el atestado (no valdría el del agente que hizo el $2 .^{\circ}$ análisis o que intervino pero no presenció lo ocurrido), y la lectura del atestado y de aquellos documentos levantados en el momento a salvo las excepciones que la propia STC enumera (FJ 2..$^{\circ}$ :

"En consecuencia, hemos afirmado con reiteración que el atestado tan sólo tiene el valor de denuncia, por lo que considerado en sí mismo se erige en objeto de prueba y no en medio de prueba (SSTC 31/1981, de 28 de julio, FJ 4; 9/1984, de 30 de enero, FJ 2), con el resultado de que los hechos que en él se afirman por funcionarios, testigos o imputados han de ser introducidos en el juicio oral a través de auténticos medios probatorios (STC 145/1985, de 28 de noviembre, FJ 1). Por esta razón, hemos dicho que no "son medios de prueba las declaraciones de la policía, vertidas en el atestado, sino que se hace necesario, de conformidad con lo establecido en los arts. 297.2 y 727 LECrim, que tales funcionarios presten declaración en el juicio oral, debiendo, en tal caso, ser apreciadas sus manifestaciones como declaraciones testificales" (SSTC 217/1989, de 21 de diciembre, FJ 2, y 33/2000, de 14 de febrero, FFJJ 5 y 6$)$.

Ello, sin embargo, no significa negar toda eficacia probatoria a las diligencias policiales que constan en el atestado, pues, por razón de su contenido, pueden incorporar datos objetivos y verificables, como croquis, planos, fotografías, que pueden ser utilizados como elementos de juicio siempre que se introduzcan en el juicio oral como prueba documental y garantizando de forma efectiva su contradicción (SSTC 107/1983, de 29 de noviembre, FJ 3; doctrina reiterada hasta 
la STC 33/2000, de 14 de febrero, FJ 5). El atestado se considera prueba documental exclusivamente en relación con estos elementos (STC 173/1997, de 14 de octubre, FJ 2.a).

Especificamente, cuando el atestado incorpora determinadas pericias técnicas realizadas por los agentes de policía, como las pruebas de alcoholemia, éstas adquieren especial relevancia y pueden alcanzar valor probatorio por sí mismas siempre que se incorporen al proceso respetando los principios de inmediación, oralidad y contradicción; la especial relevancia de estos elementos incorporados al atestado resulta, de un lado, del hecho de constituir pericias técnicas, que, al ser realizadas con instrumental técnico, tienen carácter objetivo y, de otra parte, de que, al referirse a una situación o estado que no persiste hasta la celebración de la vista, son, en consecuencia, difícilmente practicables en la misma (STC 145/1985, de 28 de noviembre, FJ 4; en sentido similar SSTC 100/1985, de 3 de octubre, FJ 2; 5/1989, de 19 de enero, FJ 2; 111/1999, de 14 de junio, FJ 5). Ahora bien, hemos precisado que la incorporación del resultado de las pruebas de alcoholemia no puede efectuarse a través de la lectura del atestado en el juicio oral cuando se cuestione la fiabilidad del resultado del test de alcoholemia o se ponga en duda el valor de ese resultado en relación con el elemento determinante del delito, esto es, la conducción bajo la influencia del alcohol (SSTC 145/1985, de 28 de noviembre, FJ 4; 145/1987, de 23 de septiembre, FJ 2); tampoco es suficiente la lectura del atestado cuando en la práctica de la prueba de alcoholemia no se haya informado al conductor del derecho que le asiste a un segundo examen alcoholimétrico y a contrastar los resultados mediante la práctica de un análisis de sangre u otro, requisitos éstos exigidos en orden a garantizar la contradicción y evitar la indefensión del sometido a la misma (SSTC 100/1985, de 3 de octubre, FJ 2; 145/1985, de 28 de noviembre, FJ 5; 145/1987, de 23 de septiembre, FJ 2; 5/1989, de 19 de enero, FJ 2; 3/1990, de 15 de enero, FFJ 1 y 2). En definitiva, a pesar de su carácter de prueba documental, las diligencias relativas a las pruebas de alcoholemia que constan en el atestado no pueden incorporarse al juicio oral mediante su lectura en los casos de ausencia de información al conductor del derecho a repetir la prueba y a contrastarla con un análisis de sangre, ni tampoco en aquellos otros en que se cuestione la fiabilidad del resultado de la prueba o el valor que al mismo quepa atribuir en orden a considerar acreditada la conducción bajo el efecto de bebidas alcohólicas" (cursiva de los autores).

En cuanto a la presunción de inocencia, también la Sentencia aporta criterios de importancia. Quizá entre ellos la irrelevancia en el proceso penal de las certificaciones y homologación de los etilómetros porque la prueba de cargo puede allegarse de otras maneras a la vista oral, máxime cuando en ella debe probarse tanto la conducción bajo los efectos del alcohol, cuanto que esa conducción causaba un peligro $\left(\mathrm{FJ} 3 \cdot^{\circ}\right)$.

"Pues bien, proyectando nuestra doctrina sobre la condena por el delito de conducción bajo el efecto de bebidas alcohólicas [art. 379 CP 1995 y art. 340 a) 1, CP 1973], y, dado que no se cuestiona que el recurrente fuera el conductor del vehículo, hemos de considerar enervada de forma constitucionalmente legítima la presunción de inocencia en la medida en que hayan resultado acreditados tanto la ingestión del alcohol, como la influencia de dicha ingestión en la conducción del 
vehículo, pues como declaramos desde la STC 145/1985, de 28 de noviembre, FJ 4, el delito no consiste en un determinado grado de impregnación alcohólica, sino en la conducción de un vehículo de motor bajo la influencia de bebidas alcohólicas (en el mismo sentido SSTC 145/1987, de 23 de septiembre, FJ 2; 22/1988, de 18 de febrero, FJ 3; 5/1989, de 19 de enero, FJ 2; 222/1991, de 25 de noviembre, FJ 2; 24/1992, de 14 de febrero, FJ 4; 111/1999, de 14 de junio, FJ 3)"

Sigue diciendo en el FJ $4 .^{\circ}$ :

"Por lo que se refiere a la impugnación del test de alcoholemia, hemos de coincidir con el Ministerio Fiscal en la falta de relevancia constitucional de la cuestión relativa a la caducidad del certificado de calibración del etilómetro con el que se realizaron las dos mediciones, sin perjuicio de que constituya, no obstante, una infracción de normas legales. Respecto de las garantías con las que debe ser practicada la prueba de alcoholemia, como acabamos de recordar, este Tribunal sólo ha otorgado relevancia a las que se dirigen a garantizar la contradicción y evitar la indefensión de quien debe practicarla, esto es, la garantía consistente en ser informado del derecho a un segundo examen alcoholimétrico y a contrastar los resultados obtenidos mediante la práctica de un análisis de sangre u otro (SSTC 145/1985, de 28 de noviembre, FJ 5; 5/1989, de 19 de enero, FJ 2; 3/1990, de 15 de enero, FFJ 1 y 2; 222/1991, de 25 de noviembre, FJ 2; 111/1999, de 14 de junio, FJ 3); pero este déficit de garantías al practicarse la prueba sólo adquiere relevancia constitucional en el seno del derecho a la presunción de inocencia cuando el resultado de la prueba de alcoholemia no se haya incorporado al juicio oral mediante la declaración de los policías que lo realizaron, pues este Tribunal ha declarado vulnerado este derecho en los casos de inexistencia de dicha declaración en el juicio oral (SSTC 145/1985, de 28 de noviembre; 148/1985, de 30 de octubre; 5/1989, de 19 de enero; $3 / 1990$, de 15 de enero), mientras que ha rechazado la existencia de dicha vulneración si los policías declararon ratificando el atestado en el juicio oral (SSTC 222/1991, de 25 de noviembre; 111/1999, de 14 de junio), o si ha sido ratificado por testigos presentes (STC 145/1987, de 29 de septiembre) o por el propio acusado (SSTC 145/1987, de 29 de septiembre; 24/1992, de 14 de febrero)" (cursiva de los autores).

Hemos dejado para el final de este apartado el recordatorio y somero análisis de la STC 161/1997 que resolvió, desestimándola, la cuestión de inconstitucionalidad formulada recepto del artículo $380 \mathrm{CP}$ que establecía el delito de negativa a someterse a las pruebas etilométricas (lo que hasta ese momento se penaba como una manifestación del delito de desobediencia a la autoridad) ${ }^{11}$.

La Sentencia, en lo que ahora interesa, niega que el sometimiento obligatorio de dichas pruebas, so pena de ser imputado de un delito singular de desobediencia, y su

11 La Sentencia aborda entre otras cuestiones las relativas a la proporcionalidad de la pena respecto de la que en este trabajo nada se va a decir porque suscita cuestiones un tanto alejadas del objeto principal de estas páginas. Sobre esta Sentencia véanse Comas de Argemir Cendra, M (1998), Cuesta Pas194 tor, P. J. (1998) y (1999), Guerrero Fernández, P. (2000), Varona Gómez, D. (2000), Miró Llinares, F A y B 
práctica resulten lesivos del derecho a no declararse culpable o declarar contra uno mismo; lo que por otro lado, como la Sentencia recuerda, ya se había dicho en ocasiones anteriores (FJ 4):

"Esta duda de constitucionalidad ha sido ya, en su esencia, expresamente abordada y resuelta por este Tribunal. La STC 103/1985 afirmaba que 'el deber de someterse al control de alcoholemia no puede considerarse contrario al derecho a no declarar, a no declarar contra sí mismo y a no confesarse culpable, pues no se obliga al detectado a emitir una declaración que exteriorice un contenido, admitiendo su culpabilidad, sino a tolerar que se le haga objeto de una especial modalidad de pericia, exigiéndole una colaboración no equiparable a la declaración comprendida en el ámbito de los derechos proclamados en los arts. 17.3 y 24.2 de la Constitución' (fundamento jurídico 3.; también, STC 76/1990, fundamento jurídico 10.; AATC $837 / 1988$, fundamento jurídico 2., y 221/1990, fundamento jurídico 2.). Contemporáneamente, la STC 107/1985 añadía que la realización de una prueba de alcoholemia no 'entraña exigencia alguna de declaración autoincriminatoria del afectado, y sí sólo la verificación de una pericia técnica de resultado incierto y que no exorbita, en sí, las funciones propias de quienes tienen como deber la preservación de la seguridad del tránsito y, en su caso, en mérito de lo dispuesto en el art. 492.1 de la Ley de Enjuiciamiento Criminal, la detención de quien intentare cometer un delito o lo estuviere cometiendo. En estos términos, la verificación de la prueba que se considera supone, para el afectado, un sometimiento, no ilegítimo desde la perspectiva constitucional, a las normas de policía, sometimiento al que, incluso, puede verse obligado sin la previa existencia de indicios de infracción, en el curso de controles preventivos realizados por los encargados de velar por la regularidad y seguridad del tránsito' (fundamento jurídico 3.; también, SSTC 22/1988, fundamento jurídico 1., y 252/1994, fundamento jurídico 4.) (cursiva de los autores).

Esta doctrina ha sido recordada en otras ocasiones con estas u otras palabras. Así, la STC 145/1987 afirmaba rotundamente que 'la determinación del grado de alcohol en sangre a través del correspondiente test de alcoholemia no es contraria a las garantías constitucionales' (fundamento jurídico 2.); el ATC 61/1983 establecía que 'sin perjuicio, naturalmente, del derecho del ciudadano a rehusar la sujeción a tal prueba y de soportar las consecuencias que del rechazo se puedan derivar' (fundamento jurídico 2.), y la STC 252/1984 reiteraba la caracterización de la prueba de alcoholemia como 'una pericia técnica en que la participación del detenido con declaraciones autoinculpadoras está ausente' (fundamento jurídico 4.). Más recientemente, la STC 197/1995 volvía a negar la catalogación de dicha prueba como declaración (fundamento jurídico 8 .)".

Doctrina que proyecta a continuación sobre el artículo 380 CP cuestionado en ese momento (FJ 5):

“Debemos ahora reiterar esta doctrina, con ocasión de la resolución de la presente cuestión y de las nuevas dudas de corrección jurídica que al respecto ha levantado el art. 380 del nuevo Código Penal. La resurrección de esta incertidumbre, por cierto, carece de apoyo en la norma cuestionada, que no sólo no establece pruebas de detección de alcohol o drogas en los conductores, como apuntábamos 
antes, sino que tampoco impone ex novo su obligatoriedad: Se limita a aumentar el rigor de las consecuencias de su incumplimiento y a elevarlas del ámbito administrativo al penal. Desde esta perspectiva no se crea propiamente un nuevo precepto jurídico sino que se modifica su sanción, lo que invita a considerar que el nuevo problema de constitucionalidad no radica en la contrariedad al art. 24 C.E. de una obligación ya preexistente y ya sometida por una u otra vía a la consideración de esta jurisdicción, sino, en su caso, en el tratamiento proporcionado del derecho afectado por la sanción".

A partir de estas premisas el TC razona, en primer lugar, que el sometimiento a las pruebas etilométricas no son en rigor una declaración o testimonio y, en consecuencia, no caen dentro de la órbita de influencia del derecho a no declararse culpable o a no autoincriminarse, y tampoco implican afectación alguna del derecho de presunción de inocencia (FJ 7):

“Tampoco menoscaban per se el derecho a la presunción de inocencia por inversión de la carga material de la prueba. Las pruebas de detección discutidas, ya consistan en la espiración de aire, ya en la extracción de sangre, en el análisis de orina o en un examen médico, no constituyen actuaciones encaminadas a obtener del sujeto el reconocimiento de determinados hechos o su interpretación o valoración de los mismos, sino simples pericias de resultado incierto que, con independencia de que su mecánica concreta no requiera sólo un comportamiento exclusivamente pasivo, no pueden catalogarse como obligaciones de autoincriminarse, es decir, como aportaciones o contribuciones del sujeto que sostengan o puedan sostener directamente, en el sentido antes dicho, su propia imputación penal o administrativa, ya que, según se dijo en la STC 76/1990 respecto de la obligación de exhibir o aportar determinados documentos contables, con ello quien se ve sometido a esas pruebas "no está haciendo una declaración de voluntad ni emite una declaración que exteriorice un contenido admitiendo su culpabilidad". En el mismo sentido se pronuncia la STC 197/1995 en relación con la obligación del titular de un vehículo de identificar al conductor presuntamente responsable de una infracción. De ahí que no exista el derecho a no someterse a estas pruebas y sí, por contra, la obligación de soportarlas".

“Esta obligación nace, en efecto, no sólo de la evidente legitimidad genérica de este tipo de actuaciones de los poderes públicos como actuaciones de indagación de la policía judicial para la detección de la comisión de delitos, sino también de una justificación análoga de las mismas cuando corresponden a la función de supervisión de la Administración de que las actividades peligrosas lícitas se desarrollen en el marco de riesgo permitido por el ordenamiento. Desde la óptica del ciudadano, y como contrapartida de la propia permisión del riesgo circulatorio, ésta se traduce en un correlativo deber de soportar estas actuaciones de indagación y control, y de colaborar con su práctica, dentro naturalmente del espacio ya reseñado que demarcan sus garantías procedimentales esenciales. En efecto, la conducción de vehículos a motor es una actividad que puede poner en grave peligro la vida y la integridad física de muchas personas, hasta llegar a convertirse en la actualidad en la primera causa de mortalidad en un segmento de edad de la población española; de ahí que, como sucede con otras muchas actividades potencialmente peligrosas, resulte plenamente justifica- 
ble que los poderes públicos, que deben velar en primerísimo lugar por la vida de los ciudadanos, supediten el ejercicio de esta actividad al cumplimiento de severos requisitos, sometan a quienes quieran desarrollarla a controles preventivos llevados a cabo por parte de las Administraciones Públicas y se anuden a su incumplimiento sanciones acordes con la gravedad de los bienes que se pretende proteger. La obligación de someterse a las pruebas de detección de alcohol u otras sustancias estupefacientes, a pesar de las dudas que pudiera suscitar el tenor literal del art. 380 Código Penal, tiene como objetivo, pues, el de comprobar si los conductores cumplen las normas de policía establecidas para garantizar la seguridad del tráfico. Dicho sometimiento no sólo no supone una autoincriminación en relación con un delito contra la seguridad en el tráfico, por lo ya expuesto, sino que constituye hoy en el nuevo Código Penal el mandato típico de un delito específico de desobediencia, respecto del cual, a su vez, frente a lo que sugiere el Fiscal, carece de sentido plantear la negativa al sometimiendo a las pruebas no como delito per se, sino como acto de autoincriminación".

“El criterio expuesto converge en lo esencial con el de la Resolución (73) 7 del Comité de Ministros del Consejo de Europa, de 22 de marzo de 1973, que indica que 'nadie podrá negarse o sustraerse a una prueba del aliento, a que se le tome una muestra de sangre o a someterse a un reconocimiento médico. Las legislaciones nacionales serán las responsables de velar por la aplicación de este principio' [punto II.2 c).] Es también acorde con el que sustenta al respecto el Tribunal Europeo de Derechos Humanos (Sentencia de 17 de diciembre de 1996, caso Saunders contra el Reino Unido, parágrafo 69) y la Comisión Europea de Derechos Humanos (asuntos 986/61 y $8.239 / 78) "$ (cursiva de los autores) ${ }^{12}$.

La STC 234/1997, que resuelve un número importante de cuestiones de inconstitucionalidad formuladas contra el mismo artículo $380 \mathrm{CP}$, reitera, en lo que ahora interesa, la Sentencia que se acaba de resumir. Acaso merezca la pena recordar que en la 234/1997 se rechaza además que el sometimiento a las pruebas etilométricas supongan afectación alguna del derecho a la intimidad personal y corporal (FJ 9):

"Otro de los motivos por los que se ha cuestionado este precepto del Código Penal es por considerarlo contrario al art. 18.1 C.E. Según se sostiene en el Auto de planteamiento de la cuestión núm. 1.135/97, la obligación de someterse a estas pruebas es contraria al derecho a la intimidad personal que consagra dicho precepto constitucional. Ahora bien, en tal caso, la pretendida inconstitucionalidad sería imputable, no al art. 380 C.P., que no regula prueba alguna -pues se limita a tipificar como delito de desobediencia la negativa a someterse a las pruebas que legalmente se establezcan con el fin de comprobar si conduce bajo el efecto de bebidas alcohólicas, drogas o cualquier otra sustancia psicotrópica-, sino a la norma que regula este tipo de pruebas, el art. 12.3 L.T.S.V., que no ha sido cuestionada formalmente ante este Tribunal. Con la particularidad de que esta norma remite su regulación al

12 Recuérdese que a esta Sentencia fueron formulados dos votos particulares, el del Magistrado Pérez Manzano, que únicamente discrepaba del examen de la proporcionalidad del nuevo tipo penal y su pena; y el del Magistrado Ruiz Vadillo que sí consideraba contrario al artículo 24 CE este tipo delictual pues en efecto vulneraba los derechos a no confesarse culpable y no autoincriminarse. 
Reglamento y a tales pruebas se refiere, en efecto, el art. 28 del Real Decreto 13/1992, de 17 de enero, por el que se aprueba el Reglamento General de Circulación.

B) Pues bien, ninguna de ellas puede estimarse contraria a la Constitución. En efecto, si la prueba consiste en un análisis de sangre, que es una intervención corporal leve (STC 207/1996, fundamento jurídico 2), es evidente que, cuando se realice de forma voluntaria, no se lesiona ni el derecho a la integridad física (art. 15.1 C.E.) ni el derecho a la intimidad corporal. Y cuando se trate de una obligación impuesta por el Juez a efecto de su contraste con otra prueba, ha de tenerse presente que esta medida está prevista por la Ley (el art. 380 C.P., que tiene carácter orgánico) y es proporcionada. Pues sirve objetivamente para determinar hechos que constituyen el objeto de un proceso penal y es necesaria a este fin; sin que existan otras medidas menos gravosas e igualmente aptas para determinar el grado de alcohol u otras sustancias en la sangre ni el sacrificio que impone resulta excesivo en comparación con la gravedad que entraña la conducción bajo sus efectos. De otro lado, si la prueba sólo consiste en la espiración de aire, tampoco es contraria a la Constitución, pues es claro que, por la parte del cuerpo afectada, difícilmente se lesiona el derecho a la intimidad corporal (SSTC 120/1990, 137/1990, 57/1994 y 207/1996).

C) No obstante, que no exista vulneración alguna del derecho a la intimidad corporal no significa que no pueda existir una lesión del derecho más amplio a la intimidad personal del que aquél forma parte, ya que esta vulneración podría causarla la información que mediante este tipo de pericia se ha obtenido. Ciertamente, cuando se obliga a un sujeto a someterse a una prueba con el fin de averiguar una determinada información se está afectando su derecho a la intimidad, ya que a través de la práctica de esa prueba se puede obtener una información que ese sujeto puede no querer desvelar. Ahora bien, para que tal afectación sea constitucionalmente relevante, $y$, por tanto, pueda considerarse lesiva del art. 18.1 C.E., es preciso-como ha señalado la STC 207/1996-, que la misma carezca de una justificación objetiva y razonable, lo que no ocurre en los supuestos que ahora se analizan. Y para comprobarlo conviene examinar esta cuestión a la luz de la doctrina que sobre la proporcionalidad ha establecido este Tribunal en la Sentencia que se acaba de citar.

Dado el peligro que entraña la conducción bajo el efecto de este tipo de sustancias es claro que existe un fin legítimo que justifica que se impongan estas medidas que pueden afectar al ámbito de la intimidad personal. Debe tenerse en cuenta que la ingestión de estas sustancias no sólo pone en peligro al sujeto que las ha consumido, sino que al llevar éste a cabo una actividad peligrosa que afecta a terceras personas, pone también en peligro la seguridad del tráfico, por lo que es indudable la existencia de un interés general en evitar que se conduzca en estas condiciones.

De igual manera se cumpliría el segundo de los requisitos indicados, ya que en este caso la medida limitativa está prevista en una norma con rango de Ley, en concreto en el art. 12 L.T.S.V. Conviene poner de relieve que para que se entienda cumplido este requisito basta con que el legislador prevea la adopción de estas medidas, sin 
que sea necesario que sea también la Ley la que lleve a cabo la regulación concreta de dichas medidas. Así lo entendió la STC 7/1994 al establecer que esta exigencia se cumplía al establecer el art. 127 C.C. la posibilidad de investigar la maternidad y paternidad mediante toda clase de pruebas, incluidas las biológicas. Y a la misma conclusión llega la STC 35/1996 al considerar que la práctica de observaciones radiológicas sobre internos como medida de seguridad tiene su fundamento en el art. 23 L.O.G.P; norma que remite al reglamento la regulación de los registros y cacheos en la persona de los internos. De ahí que, desde esta perspectiva, nada haya que objetar a las remisiones reglamentarias que pueda efectuar la Ley que prevé la posibilidad de imponer estas medidas limitativas.

$\mathrm{Y}$ por lo que se refiere al tercer requisito, también hay que entenderlo cumplido, pues aunque ciertamente en estos supuestos la autoridad judicial no interviene siempre y, en todo caso (las pruebas de detección de las posibles intoxicaciones por alcohol las llevan a cabo los Agentes encargados de la vigilancia del tráfico), este Tribunal ha admitido la posibilidad de que "la Ley pueda autorizar a la Policía judicial para disponer, por acreditadas razones de urgencia y necesidad, la práctica de actos que comporten una simple inspección o reconocimiento o, incluso, una intervención corporal leve, siempre y cuando se observen en su práctica los requisitos dimanantes de los principios de proporcionalidad y razonabilidad' [STC 207/1996, fundamento jurídico 4, C)]. En los supuestos que ahora se analizan existe la habilitación legislativa (art. 12 L.T.S.V.), y también se dan las circunstancias de urgencia y necesidad, pues se trata de averiguar si el conductor está conduciendo bajo la influencia de estas sustancias y ello sólo puede apreciarse si la prueba se practica en el momento en que es requerido para ello; pues si se practicase esta prueba en un momento posterior podría suceder que el efecto de estas sustancias hubiera ya desaparecido, con lo cual su práctica carecería de sentido. Conviene señalar, de otra parte, que el que sean los Agentes encargados del control del tráfico quienes tienen encomendada por la Ley la realización de estas pruebas, y no a la Policía judicial -que es la excepción que contempla la STC 207/1996-, es una cuestión que carece de relevancia ya que no es constitucionalmente exigible que sea el Juez quien tenga que autorizar esta medida limitativa, pudiéndola adoptar, siempre que una Ley expresamente la habilite, la autoridad que, por razón de la materia de que se trate, sea la competente. Pues, como ha señalado la STC 207/1996, "no existe en la Constitución en relación con las inspecciones e intervenciones corporales, en cuanto afectantes a los derechos a la intimidad (art. 18.1 C.E.) y a la integridad física (art. 15 C.E.), reserva absoluta alguna de resolución judicial” (cursiva de los autores).

\section{ALGUNAS CONCLUSIONES QUE CABE EXTRAER DE LA JURISPRUDENCIA DEL TC Y SU PROYECCIÓN SOBRE LAS ALCOHOLEMIAS EN VÍA ADMINISTRATIVA}

Tras la lectura de estos hitos, no cabe duda de la constitucionalidad de las pruebas etilométricas en cualquiera de sus modalidades previstas legal y reglamentariamente, de la punición administrativa y penal de la conducta de conducir bajo los efectos del alcohol, y de la punición de la negativa a someterse a dichas pruebas. 
La cuestión estriba en saber si en vía administrativa, vista la modalización con la que se aplica el 24.2 CE a los expedientes sancionadores, valen las mismas exigencias que en la vía penal: dónde se encuentran y dónde se separan los estándares constitucionales de garantías. A nuestro juicio, la naturaleza bien distinta de una y otra expresión del ius puniendi del Estado explican, y así también lo ha dicho el TC no sin cierta falta de precisión, las distintas intensidades con las que aquéllas penetran en el derecho Administrativo Sancionador.

Es más, el TC ha dejado meridianamente claro que el sometimiento a las pruebas etilométricas no supone ni una detención del artículo 17.3 CE, ni una invasión del derecho a la intimidad corporal y personal del sometido a dichas pruebas, ni una suerte de medida coercitiva para la autoincriminación, ni remedio de declaración inculpatoria, ni afecta a la presunción de inocencia, ni afecta al principio de igualdad cuando se somete sin distinción a cualquier conductor, presente o no signos de conducir bajo los efectos del alcohol, y sobre cualquiera de ellos pesa la amenaza de cometer el delito previsto en el artículo $380 \mathrm{CP}$ originariamente, hoy es el artículo $383 \mathrm{CP}$, si se niegan a someterse a las pruebas etilométricas.

Repasemos los corolarios que cabe extraer de la jurisprudencia constitucional. Para el TC las pruebas etilométicas son expresión del ejercicio legítimo de la potestad de policía del Estado en materia de seguridad vial a la que todos los ciudadanos estamos sometidos. Potestad de policía en el ámbito de la seguridad vial de la que derivaría la obligación de someterse a las pruebas etilométricas, de ser requeridos para ello, y de ser sancionado en el caso de negarse a ellas.

EI TC ha reiterado sin flaquezas ni titubeos que el control de alcoholemia constituye una pericia técnica de resultado indeterminado y naturaleza indagatoria, que deben ser objeto de prueba mediante la ratificación de su práctica y resultado por los Agentes que hayan intervenido personalmente en ella, o con su incorporación al expediente administrativo sancionador. A esa pericia se le puede atribuirse el carácter de prueba pericial. Pericia que suele incorporarse al atestado policial, que a su vez se incorpora al expediente administrativo instruido al efecto, razón por la que, sabido que ese atestado solo tiene el valor de denuncia, dado que no cabe su reproducción, bien puede llegar a producir los efectos de una prueba preconstituida, siempre que observe determinadas exigencias, que también ha fijado el TC: respeto al procedimiento fijado legal y reglamentariamente para la prácticas de las pruebas etilométricas, información al conductor de sus resultados y derechos, y que el conductor pueda conocerlos y alegar en su contra. Cumplidas estas exigencias, la prueba es válida y puede emplerase como prueba de cargo.

A nuestro juicio, en la vía administrativa, el acento debe ponerse justo en el cumplimiento escrupuloso del modo legal o reglamentariamente dispuesto para la práctica de la pericia etilométrica y su incorporación al expediente administrativo sancio-

200 nador. Parafraseando al TC, informar al interesado de su derecho a un segundo 
examen alcoholimétrico y a la práctica médica de un análisis de sangre, respetar el due process of law previsto en la LSV y su RLSV, y la ratificación de los agentes actuantes del cómo y resultado de la pericia, basta y sobra para la imposición de la sanción del artículo 65.5 c) LSV. Ahora bien, en vía administrativa, al ser una sanción formal y darse solo con el resultado objetivo de una medición, la fiabilidad del etilómetro es, como veremos, relevante y decisiva.

Recuérdese una vez más que para el TC, la temporal retención para la práctica de las mediciones etilométricas no es una detención del artículo 17.3 CE. Ni siquiera en el ámbito penal se ha considerado que esa pruebas y la singular obligación de tolerar su práctica por parte de su sujeto pasivo afecten al derecho a no declararse culpable y a autoincriminarse; menos aún para el caso de la sanción administrativa, donde, a nuestro juicio, estas garantías se proyectan con mucha menor intensidad. El TC considera que la práctica de la prueba al requerir una actitud pasiva es una mera diligencia realizada sobre el sujeto que tampoco vulnera su intimidad en ninguna de sus formas, ni su integridad física o moral. Otro tanto cabría decir para la vía administrativa. Acaso pudiera parecer que justo esos derechos a no declararse culpable y no autoincriminarse se cumplen y ejercen, tanto en la vía penal como la administrativa, con esa pasividad del sujeto, el cual no puede ser compelido a colaborar activamente en la práctica de dichas pruebas.

Tampoco el TC albergue duda alguna sobre la constitucionalidad del delito consistente en negarse a su práctica (artículo $383 \mathrm{CP}$ ). Pues lo mismo debe decirse de su manifestación administrativa del artículo 21 RLSV. En esta su manifestación administrativas, a nuestro juicio, puede traerse aquí lo razonado recientemente por Casino Rubio 2(2010, p. 179 y ss). En efecto, en rigor de esa negativa, como del silencio del propietario del vehículo a identificar a su conductor, no cabe extraer una presunción jurídica (de muy difícil encaje en el derecho sancionador, como bien se sabe y ha apuntado el TC en diversas ocasiones) que termine por invertir la carga de la prueba incluso en los expedientes administrativos sancionadores ${ }^{13}$. La negativa a someterse a la prueba etilométrica, en vía administrativa, es, así lo creemos, expresión de una conducta contraria al deber general de sujeción a la policía administrativa, y del singular en el ámbito de la seguridad vial (que bien puede asemejarse al caso de la negativa a identificarse a requerimiento de los Agentes de la Autoridad del artículo 20.2 de la Ley Orgánica 1/1992, de 21 de febrero, sobre Protección de la Seguridad Ciudadana, sobre cuya constitucionalidad se pronunció en sus FFJJ $5 .^{\circ}$ y $6 .^{\circ}$ la STC 341/1993). Y como tal así debe ser sancionada en vía administrativa; no por considerar que esa negativa es presunción de la intoxicación, sino una simple desobediencia a una orden legítima expresada por un agente de la autoridad en el ejercicio de sus atribuciones legal y reglamentariamente atribuidas.

El cumplimiento de estos extremos, sumado a la ratificación por los agentes actuantes de lo reflejado en el atestado ( $y$ aquellos otros documentos y pericias que lo

13 Véase Casino Rubio, 2(2010), p. 214 y ss. 
acompañen), y su incorporación al oportuno expediente sancionador, debiera, a nuestro juicio, ser suficiente para considerar que la imposición de la sanción administrativa no merece reproche constitucional alguno.

\title{
V. DOS MUNDOS Y UN NON BIS IN IDEM
}

Conviene apuntar brevemente la disociación de las figuras delictivas invocadas al objeto de precisar que, pese a los indefectibles vínculos, ambos tipos constituyen, como delictivos, comportamientos distintos lesivos de bienes jurídicos diversos, siendo la realidad que, si el legislador ha resuelto sancionar separadamente dichas conductas, ha sido en el entendimiento de procurar contribuir a una mayor seguridad en el tráfico, confiriendo una protección a través tanto de ataques a dicha seguridad de manera inmediata como mediata, así como por medio de la salvaguarda del principio de autoridad y protección del orden público.

Es relevante la proyección de esta diferencia en lo relativo al alcance de la conculcación del principio non bis in idem reconocido por el Tribunal Constitucional como un derecho fundamental del sancionado al entender que está íntimamente unido a los principios de legalidad y tipicidad de las infracciones consagrados en el artículo 25 de la CE. Si bien para que quepa hablar de la vulneración de tal principio se requiere la existencia de una doble sanción por unos mismos hechos y, sin dejar de reconocer lo relacionadas que están las conductas referidas, se trata de conductas distintas no necesitando la segunda de la existencia de la primera; tal como se expresa la STC 1/2009: "La disimilitud de conductas típicas excluye la vulneración del principio non bis in idem."

En lo que ahora toca, la STC 2/2003 vino a corregir las controvertidas SSTC 177/1999 y 152/2001 sobre el qué y el cómo del non bis in idem precisamente en el ámbito de las alcoholemias. Afirmó en su FJ 3. ${ }^{\circ}$ :

\begin{abstract}
"En definitiva, hasta ahora este Tribunal sólo ha reconocido de manera expresa autonomía al derecho a no ser sometido a un doble procedimiento sancionador cuando se trata de un doble proceso penal (STC 159/1987, de 26 de octubre; ATC 1001/1987, de 16 de septiembre), de modo que la mera coexistencia de procedimientos sancionadores-administrativo y penal- que no ocasiona una doble sanción no ha adquirido relevancia constitucional en el marco de este derecho (STC 98/1989, de 1 de junio; AATC 600/1987, de 20 de mayo; 413/1990, de 26 de noviembre)" (la cursiva es de los autores).
\end{abstract}

A lo que debe añadirse las consecuencias que esta interdicción supone para el ejercicio de la potestad sancionadora de la Administración Pública (FJ $3 .^{\circ}$ ):

"Entre los límites que la potestad sancionadora de la Administración encuentra en el art. $25.1 \mathrm{CE}$, en lo que aquí interesa, se declaró la necesaria subordinación de los actos de la Administración de imposición de sanciones a la Autoridad judicial. 
De esta subordinación deriva una triple exigencia: 'a) el necesario control a posteriori por la Autoridad judicial de los actos administrativos mediante el oportuno recurso; b) la imposibilidad de que los órganos de la Administración lleven a cabo actuaciones o procedimientos sancionadores, en aquellos casos en que los hechos puedan ser constitutivos de delito o falta según el Código penal o las leyes penales especiales, mientras la Autoridad judicial no se haya pronunciado sobre ellos; c) la necesidad de respetar la cosa juzgada"'.

El problema es que el artículo 65.1 LSV, remite al artículo 72 cuando "las acciones u omisiones" reguladas en esta ley "puedan constituir delitos o faltas" tipificadas por el CP. Pero es que la infracción muy grave de la letra c del apartado 5 del artículo 65 prevé la sanción de la conducción por encima de cierta tasa, es decir, por una razón objetiva, pero el CP en su artículo 379.2 lo que sanciona es también sobrepasar un límite objetivo, de manera que el derecho administrativo sancionador castiga un grado de disvalor de la conducta, y el penal sanciona la misma conducta pero si es aún más disvaliosa, lo que a su vez depende de una medida objetiva de la que resulta la presunción de que se actúa antijurídicamente de manera más gravosa. Además el CP mantiene una cláusula general que castiga el genérico peligro que puede provocar en el tráfico conducir bajo los efectos del alcohol (u otras sustancias) que vuelve a colar por la ventana lo que se había sacado por la puerta: evitar solapamientos. La distinción de los dos ámbitos con el criterio objetivo de la tasa, que permitía distinguirlos con suma claridad, se ha roto con esa cláusula general, reproduciendo de nuevo los mismos problemas a los que se enfrenta la jurisprudencia del non bis in idem.

Esa misma STC 2/2003 expuso los términos de esta cuestión con suma claridad $\left(\mathrm{FJ} 4 \cdot^{\circ}\right)$ :

b) De la mera comparación de ambas normas deriva que, como afirma en los fundamentos jurídicos segundo y tercero la Sentencia de la Audiencia Provincial de A Coruña de 20 de enero de 2000 , el delito contenido en el art. 379 CP no constituye una infracción meramente formal, como sí lo es la que tipifica el art. 12.1 Real Decreto $339 / 1990$, pues para imponer la pena no basta con comprobar a través de la pertinente prueba de alcoholemia que el conductor ha ingerido alcohol o alguna otra de las sustancias mencionadas en el mismo, sino que es necesario que se acredite que dicha ingestión ha afectado a la capacidad psicofísica del conductor, y, consecuencia de ello, a la seguridad en el tráfico, que es el bien jurídico protegido por dicho delito.

Y añade la Sentencia casi a renglón seguido:

La ausencia de carácter formal del delito de conducción bajo el efecto de bebidas alcohólicas ha sido resaltada por este Tribunal en reiteradas ocasiones. Así, desde la STC 145/1985, de 28 de octubre, hemos declarado en relación con el antiguo delito del art. 340 bis a) 1 CP anterior, idéntico al actual art. 379 CP, que el supuesto delictivo "no consiste en la presencia de un determinado grado de impregnación alcohólica, sino en la conducción de un vehículo de motor bajo la influencia de bebidas alcohólicas" (FJ 4; en el mismo sentido SSTC 148/1985, de 30 de 
octubre, FJ 4; 145/1987, de 23 de septiembre, FJ 2; 22/1988, de 18 de febrero, FJ 3.a; 5/1989, de 19 de enero, FJ 2; 222/1991, de 25 de noviembre, FJ 2); de modo que para la apreciación del delito no resulta imprescindible ni suficiente la prueba de impregnación alcohólica (SSTC 24/1992, de 14 de febrero, FJ 4; 252/1994, de 19 de septiembre, FJ 5). Por ello en la STC 111/1999, de 14 de junio, FJ 3, afirmamos que "se trata de una figura delictiva similar, pero no idéntica, a la correlativa infracción administrativa, caracterizándose aquélla por la exigencia de un peligro real para la seguridad del tráfico". De otra parte, como sostuvimos en la STC 161/1997, de 2 de octubre, FJ 13, "la conducción bajo la influencia de las drogas o del alcohol no sólo constituye un comportamiento delictivo autónomo, sino también una forma de comportamiento imprudente que puede lesionar la vida y la integridad física de las personas", de modo que se dirige tendencialmente también a la protección de estos bienes jurídicos.

Sin embargo, la infracción administrativa tiene carácter formal y se aplica de forma que pudiéramos llamar automática. Consecuencia de ello es que para la realización de la infracción administrativa y la imposición de la correspondiente sanción basta con acreditar, mediante la prueba de alcoholemia, que la ingestión de alcohol supera la tasa fijada de forma reglamentaria, no exigiéndose la acreditación de que en el caso concreto dicha ingestión haya tenido alguna influencia en la capacidad psico-física del conductor ni, derivado de ello, en su forma de conducción o en la seguridad del tráfico vial. Por ello, en el expediente administrativo no hay referencia alguna a la influencia de la ingestión del alcohol en la capacidad psicofísica del conductor. En el mismo sólo constan como hechos la ingestión de alcohol y la tasa de alcohol por litro de aire expirado resultado de las dos pruebas realizadas -0,86 y 0,81 mgrs. / litro de aire-, así como el precepto infringido -art. 20.1 Reglamento general de circulación en relación con el art. 12.1 LSV. Tampoco se menciona el dato de que el conductor era penalmente reincidente ya que había sido previamente sancionado por delito contra la seguridad del tráfico en Sentencia firme de 13 de junio de 1996.

c) Esta diferencia esencial entre la infracción administrativa y el delito, que sustenta la legitimidad constitucional de la diferente entidad de las sanciones previstas para ambas, pues sólo así éstas pueden considerarse ajustadas a las exigencias que derivan del principio de proporcionalidad de las sanciones, no puede, sin embargo, conducir a sostener la ausencia de identidad que determinaría la inaplicación de la interdicción constitucional. En efecto, ambas infracciones, administrativa y penal, comparten un elemento nuclear común-conducir un vehículo de motor habiendo ingerido alcohol, superando las tasas reglamentariamente determinadas-, de modo que al imponerse ambas sanciones de forma cumulativa, dicho elemento resulta doblemente sancionado, sin que dicha reiteración sancionadora pueda justificarse sobre la base de un diferente fundamento punitivo, dado que el bien o interés jurídico protegido por ambas normas es el mismo -la seguridad del tráfico como valor intermedio referencial; la vida e integridad física de todos, como bienes jurídicos referidos. Se trata de un caso en el que el delito absorbe el total contenido de ilicitud de la infracción administrativa, pues el delito añade a dicho elemento común el riesgo para los bienes jurídicos vida e integridad física, inherente a la conducción realizada por una persona con sus facultades psico-físicas disminuidas, debido a la efectiva influencia del alcohol ingerido (la cursiva es de los autores). 
El propio TC en esta relevante Sentencia concluye precisamente que, en el caso de autos, materialmente solo se le impuso una al infractor al haber compensado las sanciones administrativa y penal. Sin embargo, desarrolla estas interesantes reflexiones con una importante llamada al Legislador:

Desde la perspectiva material del derecho fundamental garantizado en el art. 25.1 CE, el núcleo esencial de la garantía en él contenida reside en impedir el exceso punitivo en cuanto sanción no prevista legalmente; de modo que, ni de la infracción de una regla procesal -la no suspensión del expediente administrativo prevista en el art. 7.1 y 2 RPS-, ni de la eventual falta de reconocimiento del efecto de cosa juzgada de la resolución sancionadora, deriva con carácter automático la lesión de la prohibición de incurrir en bis in idem sancionador. En el caso no puede afirmarse que se hayan impuesto dos sanciones al recurrente, una en vía administrativa y otra en vía penal, pues materialmente sólo se le ha impuesto una sanción...

No obstante, no puede dejar de reconocerse que los órganos penales, al enjuiciar el caso, se encontraban en una situación paradójica, pues, aunque no podían dejar de condenar penalmente al recurrente, dado su sometimiento estricto a la ley en el ejercicio de su función jurisdiccional (art. 117.1 CE), tampoco podían dejar de ser conscientes de que la sanción penal por ellos impuesta al mismo podía suponer una reiteración sancionadora constitucionalmente prohibida por el art. 25.1 CE. El hecho de que la legislación no prevea expresamente solución para los casos en los que la Administración no suspenda el expediente administrativo, estando un procedimiento penal abierto, puede explicar su actuación. Sólo al legislador corresponde establecer los mecanismos normativos de articulación del ejercicio de la potestad punitiva por la Administración y por la jurisdicción penal para evitar la reiteración sancionadora y contemplar las consecuencias que deriven de su incumplimiento.

Atendiendo a los límites de nuestra jurisdicción de amparo, una solución como la adoptada en este caso por el órgano judicial no puede considerarse lesiva de la prohibición constitucional de incurrir en bis in idem sancionador, dado que la inexistencia de sanción desproporcionada en concreto, al haber sido descontada la multa administrativa y la duración de la privación del carné de conducir, permite concluir que no ha habido una duplicación -bis- de la sanción constitutiva del exceso punitivo materialmente proscrito por el art. 25.1 CE. Frente a lo sostenido en la STC 177/1999, de 11 de octubre (FJ 4)... En definitiva, hemos de precisar que en este caso no hay ni superposición ni adición efectiva de una nueva sanción y que el derecho reconocido en el art. 25.1 CE en su vertiente sancionadora no prohíbe el "doble reproche aflictivo", sino la reiteración sancionadora de los mismos hechos con el mismo fundamento padecida por el mismo sujeto (cursiva de los autores).

¿Y el Legislador ha cumplido con esa llamada? Bien parece que solo en parte, pues el problema persiste como ya se ha apuntado.

Otra faceta importante de esta interdicción estriba en si la sustanciación de un procedimiento sancionador administrativo previo al penal implica una suerte de "cosa juzgada" administrativa que impediría a la jurisdicción penal iniciar las oportunas dili- 
gencias y enjuiciar, y en su caso sancionar de nuevo y con posterioridad, unos hechos que ya lo había sido en vía administrativa. La respuesta del TC es meridiana (FJ 8.):

En efecto, la interdicción constitucional de apertura o reanudación de un procedimiento sancionador cuando se ha dictado una resolución sancionadora firme, no se extiende a cualesquiera procedimientos sancionadores, sino tan sólo respecto de aquéllos que, tanto en atención a las características del procedimiento -su grado de complejidad-como a las de la sanción que sea posible imponer en él-su naturaleza y magnitud- pueden equipararse a un proceso penal, a los efectos de entender que el sometido a un procedimiento sancionador de tales características se encuentra en una situación de sujeción al procedimiento tan gravosa como la de quien se halla sometido a un proceso penal. Dos son las razones que avalan esta limitación. De un lado, la lógica que impone el principio de proporcionalidad, en cuanto criterio de ponderación del contenido de los derechos fundamentales. De otro, la necesariamente matizada traslación de las garantías del proceso justo al ámbito del procedimiento administrativo sancionador. Como tiene declarado este Tribunal, las garantías procesales constitucionalizadas en el art. 24.2 CE son de aplicación al ámbito administrativo sancionador "en la medida necesaria para preservar los valores esenciales que se encuentran en la base del precepto, y la seguridad jurídica que garantiza el art. 9 de la Constitución"; de modo que la traslación de las garantías del proceso justo al procedimiento sancionador no conlleva su aplicación literal "sino con el alcance que requiere la finalidad que justifica la previsión constitucional" (STC 18/1981, de 8 de junio, FJ 2; reiterado entre otras en STC 14/1999, de 22 de febrero, FJ 3), y se condiciona a que se trate de garantías que "resulten compatibles con la naturaleza del procedimiento administrativo sancionador" (SSTC 197/1995, de 21 de diciembre, FJ 7; 14/1999, de 22 de febrero, FJ 3).

De otra parte, hemos de reiterar que, como resulta del párrafo segundo del art. 4 del Protocolo 7 CEDH y de nuestra jurisprudencia (STC 159/1987, de 26 de octubre), la interdicción de doble procedimiento sancionador sólo se incumple si los dos procedimientos han sido sustanciados con las debidas garantías, de modo que un primer procedimiento tramitado sin respetar la prioridad legal del orden jurisdiccional penal no impide un segundo procedimiento sancionador.

Finalmente, también el TC resuelve la cuestión relativa a si, en estos casos, ha lugar a la anulación de la segunda de las sanciones impuestas. La respuesta del TC vuelve a ser clara, no hay razón constitucional que avale esa conclusión (FJ 9 y 10):

Si bien todo lo expuesto es suficiente en orden a la desestimación de la concreta pretensión de amparo de vulneración de los derechos fundamentales del recurrente, resulta pertinente responder a una idea que subyace a la demanda de amparo, pues, de considerarse ratificada por este Tribunal, tendría un importante alcance en la ordenación de los procedimientos sancionadores -administrativo y penal. Nos referimos a que de la prohibición de incurrir en bis in idem sancionador -ya sea sustantivo o procesal- contenida en el art. $25.1 \mathrm{CE}$, y en su relación con el art. 24.2 CE, deriva siempre la anulación de la segunda sanción que se impone. Esta consecuencia, sin embargo, no puede ser extraída de la norma constitucional. Varias razones sustentan esta afirmación. 
De un lado, no puede obviarse el hecho de que con carácter general la Administración sancionadora debe paralizar el procedimiento si los hechos pueden ser constitutivos de infracción penal -art. 7.2 RPS-, y que, en el caso, la Administración actuó con infracción de lo previsto en dicha disposición y en el art. 65.1 LSV. Dicha infracción legal, no obstante, tiene relevancia constitucional por cuanto estas reglas plasman la competencia exclusiva de la jurisdicción penal en el conocimiento de los hechos constitutivos de infracción penal y configuran un instrumento preventivo tendente a preservar los derechos a no ser sometido a un doble procedimiento sancionador -administrativo y penal- y a no ser sancionado en más de una ocasión por los mismos hechos.

La decisión sobre qué hechos han de ser objeto de sanción penal compete en exclusiva al poder legislativo (por todas SSTC 341/1993, de 18 de noviembre, FJ 3; 55/1996, de 28 de marzo, FJ 6; 161/1997, de 2 de octubre, FJ 9). Pero, una vez que el legislador ha decidido que unos hechos merecen ser el presupuesto fáctico de una infracción penal y configura una infracción penal en torno a ellos, la norma contenida en la disposición administrativa deja de ser aplicable y sólo los órganos judiciales integrados en la jurisdicción penal son órganos constitucionalmente determinados para conocer de dicha infracción y ejercer la potestad punitiva estatal. Esta conclusión se alcanza desde el art. 25 de la Constitución en relación con el art. 117 de la misma. El art. 25 de la Constitución contiene dos límites a la potestad sancionadora de la Administración. Su párrafo tercero contiene un límite expreso que reside en la imposibilidad de que la Administración civil imponga "sanciones que directa o subsidiariamente impliquen privación de libertad"; y su párrafo primero contiene un límite implícito que afecta al ejercicio de la potestad sancionadora de la Administración y consiste en que ésta sólo puede ejercerse si los hechos no son paralelamente constitutivos de infracción penal, pues en estos casos de concurrencia normativa aparente, de disposiciones penales y administrativas que tipifican infracciones, sólo la infracción penal es realmente aplicable, lo que determina que el único poder público con competencia para ejercer la potestad sancionadora sea la jurisdicción penal. Cuando el hecho reúne los elementos para ser calificado de infracción penal, la Administración no puede conocer, a efectos de su sanción, ni del hecho en su conjunto ni de fragmentos del mismo, y por ello ha de paralizar el procedimiento hasta que los órganos judiciales penales se pronuncien sobre la cuestión.

En el caso analizado, ha de tenerse en cuenta que el art. 65.1 LSV, no sólo dispone la paralización del procedimiento administrativo en virtud de la subsidiariedad sancionadora de la Administración, sino también que los hechos sólo "tienen el carácter de infracción administrativa” si no son constitutivos de delito o falta. En efecto, dicho artículo establece que las "acciones u omisiones contrarias a esta Ley o a los reglamentos que la desarrollan, tendrán el carácter de infracciones administrativas y serán sancionadas en los casos, forma y medida que en ella se determinan, a no ser que puedan constituir delitos o faltas tipificadas en las leyes penales, en cuyo caso la Administración pasará el tanto de culpa al orden jurisdiccional competente y se abstendrá de seguir el procedimiento sancionador mientras la autoridad judicial no dicte sentencia firme". Por consiguiente, en el caso, habida cuenta de que los hechos reunían los elementos para ser calificados de delito, la Administración no podía imponer la sanción correspondiente a la infracción administrativa, que devino inaplicable. La subsunción de los hechos en la disposición administrati- 
va se efectuó, entonces, desconociendo el principio de legalidad sancionadora (art. 25.1 (E) y la competencia exclusiva de la jurisdicción penal para ejercer la potestad punitiva (art. 25.1 CE en relación con el art. 117.3 CE).

En conclusión, la cuestión atinente a cuál es el órgano sancionador que actúa en primer lugar tiene relevancia constitucional, a pesar de lo sostenido en la STC 177/1999, de 11 de octubre (FJ 5), y en consonancia con la declaración efectuada por la STC 77/1983, de 3 de octubre (FJ 3), acerca de la "imposibilidad de que los órganos de la Administración lleven a cabo actuaciones o procedimientos sancionadores, en aquellos casos en que los hechos puedan ser constitutivos de delito o falta según el Código penal o las leyes penales especiales, mientras la Autoridad judicial no se haya pronunciado sobre ellos" (FJ 9)

"Una segunda razón avala la afirmación de que de la prohibición constitucional de incurrir en bis in idem no deriva la anulación de la segunda sanción o del segundo procedimiento sancionador. Esta reside en que la declaración de responsabilidad penal se efectúa en un proceso en el que rigen garantías específicas integradas en el derecho a un proceso con todas las garantías (art. 24.2 CE) que repercuten en el contenido del derecho a la presunción de inocencia (art. 24.2 CE), mientras que la declaración de responsabilidad por infracción administrativa se realiza en un procedimiento en el que tal derecho se aplica de forma modalizada, lo que implica un menor contenido garantista del mismo (por todas SSTC 18/1981, de 8 de junio, FJ 2; 7/1998, de 13 de enero, FJ 5; 14/1999, de 22 de febrero, FJ 3)" (FJ 10) ${ }^{14}$.

\section{LAS SENTENCIAS DEL TS DE 9 DE SEPTIEMBRE DE 1999 Y DE 22 DE MARZO DE 2002}

Ponemos nuestro énfasis a continuación en la esencia más significativa de la jurisprudencia del Tribunal Supremo: las SSTS 3/1999, de 9 de septiembre y 1/2002, de 22 de marzo.

Dentro de la común tipificación que se recoge en ambas sentencias la situación punto de partida de los hechos es diversa. En la primera concurre una negativa a someterse a la prueba de alcoholemia en un control preventivo y, en la segunda, todo acontece bajo el prisma inicial de un accidente de tráfico tras el cual, advertido por los agentes halitosis alcohólica en el conductor del vehículo y practicada la prueba de muestreo, aquél se niega a practicar la segunda medición.

La Sentencia de 9 de septiembre de 1999 traza en sus fundamentos de derecho la polémica evolución del entonces tipo de desobediencia grave del artículo $380 \mathrm{CP}$,

14 Sin embargo, esta Sentencia tiene un voto particular firmado por el Magistrado Pérez Manzano sumamente relevante que defiende el criterio sentado por la doctrina de las dos Sentencias que ésta pretende enmendar, y que pone, permítasenos la expresión, el dedo en la llaga de la cuestión. No solo en la dimensión formal relativa a la articulación de ambas jurisdicciones, cuanto también en la material sobre el 208 evidente solapamiento material de las sanciones, 
poniendo primero el acento en las críticas vertidas durante la andadura parlamentaria del CP de 1995 para centrarse después, y una vez entrado en vigor dicho código, en el planteamiento de las cuestiones de inconstitucionalidad rechazadas por la Sentencia del Tribunal Constitucional de 2 de octubre de 1997 y referidas en general al derecho de defensa, a la presunción de inocencia y al principio de proporcionalidad, y en particular, al derecho del acusado a no declarar y a no confesarse culpable; todo ello sin obviar las enfrentadas posturas de la doctrina en lo tocante a la ubicación del precepto, a su redundancia al estar ya tipificado el delito de desobediencia y, a su atentado al principio de proporcionalidad al punir más gravemente el acto de la desobediencia propiamente dicha que el mismo delito cuya comisión se trata de prevenir con dicho precepto.

En cuanto a los fundamentos centrales del fondo del asunto se hacen pivotar sobre dos pilares principales:

1. Su pronunciamiento en cuanto a que para la comisión del delito previsto en el artículo 379 CP no basta con conducir con una determinada tasa de alcoholemia, sino que es menester que el conductor lo haga "bajo la influencia" del alcohol, o de cualesquiera otras de las sustancias legalmente previstas en el citado precepto, con indudable alteración de sus facultades psíquicas y físicas, en relación con sus niveles de percepción y reacción.

2. Su pronunciamiento en lo relativo al alcance de la figura delictiva de la negativa a someterse a las pruebas de alcoholemia, de modo que si tal negativa se produce en un control preventivo, sin que ha precedido riesgo para la circulación ni el conductor presente síntomas de encontrarse bajo los efectos de bebidas alcohólicas, aquélla será sancionada en vía administrativa; por el contrario, si la negativa va precedida de una situación de riesgo para la circulación o el conductor presenta síntomas de encontrarse bajo los efectos de bebidas alcohólicas, la negativa será constitutiva de un delito de desobediencia previsto en el artículo $380 \mathrm{CP}$.

La Sentencia de 22 de marzo de 2002 hace acopio de las líneas argumentales de la anterior y tomando como pauta dicho acervo razona la insuficiencia de la primera prueba practicada para considerar acreditado el tipo del artículo $379 \mathrm{CP}$ así como la entidad de infracción penal de ciertos supuestos de negativa a someterse a las pruebas de alcoholemia, concretándolos en aquellos casos en que los conductores estén implicados en un accidente o cuando conduzcan con síntomas que permitan razonablemente presumir que conducen bajo la influencia de bebidas alcohólicas.

\section{LA REGULACIÓN DE LA ALCOHOLEMIA EN LA LEGISLACIÓN VIGENTE}

En las consideraciones iniciales de este artículo apuntábamos ya las recientes modificaciones habidas tanto en los tipos penales como en la regulación administrativa. 
A modo de sinopsis, resta por reflejar las conexiones entre algunas conductas y las concordancias administrativas de aplicación. Si la conducta tipificada en el artículo 379.2 CP se vincula con el artículo 12.1 LSV que prohíbe circular por las vías públicas con tasas superiores a las que se reglamentariamente se establezca de bebidas alcohólicas, véase el artículo 20.1 RLSV, también hace lo propio con la obligatoriedad que el artículo 12.2 LSV en concordancia con los artículos 20 a 24 RLSV prevé de someterse a las pruebas de detección de la alcoholemia e, igualmente guarda conexión con la conducta de la negativa al sometimiento a tales pruebas, tipificada en el artículo $383 \mathrm{CP}$.

Analizada la constitucionalidad del deber de someterse al control de alcoholemia, procede relacionar la negativa referida con los cuatro supuestos que prevé el artículo $21 \mathrm{RLSV}$ : caso de conductor implicado en un accidente de circulación como posible responsable y de quienes conduzcan con síntomas de embriaguez evidentes, denuncia por infracción de tráfico y control preventivo de alcoholemia, cuya delimitación jurisprudencial ya ha sido subrayada.

Asimismo, es de significar que el reglamento en su artículo 24 dispone que si el conductor se negare a someterse a las pruebas será puesto a disposición judicial si los hechos revisten caracteres delictivos, usualmente por presentar síntomas evidentes de haber conducido bajo la influencia de bebidas alcohólicas. Consecuencia de dicha negativa es también la previsión de los artículos 25 RLSV y 70.1 in fine LSV, por virtud de los cuales los agentes pueden proceder a la inmediata inmovilización del vehículo

Sin embargo, no debemos soslayar que aún partiendo de las premisas antedichas se alza como elemento primordial, en cuanto garante de los derechos ciudadanos, la acreditación de dicha negativa, respecto a lo cual ha sido la jurisprudencia quien ha venido delimitando el acontecer habitual, de modo que es preciso que dicha negativa lo sea tras el requerimiento de la autoridad y la advertencia clara y comprensible por parte de los agentes de la responsabilidad penal que en su caso pueda acarrear y, que venga expresada a través de actos concluyentes, sean explícitos y contundentes o inferidos de actos reiterados derivados de actitudes desobedientes que impliquen pasividad al objeto de no dar cumplimiento al mandato de la autoridad, así se colige de la doctrina jurisprudencial emanada entre otras de las siguientes Sentencias: Sentencias de la Audiencia Provincial de Guipúzcoa, Sección Segunda, n. 을 2005 de 20 de mayo, la de Castellón, Sección Primera, n. ${ }^{\circ}$ 545/2005 de 7 de diciembre, y la Sentencia del TS de 14 de junio de 2002.

\section{EL PROCEDIMIENTO EN LAS ALCOHOLEMIAS Y LA APLICACIÓN EN LOS CASOS DE ALCOHOLEMIA DE LAS GARANTÍAS DEL ARTÍCULO 24.2 CE}

Determinadas las personas que están obligadas a someterse a una investigación de alcoholemia, artículos 12.2 LSV y 21 RLSV, el reglamento desarrolla minuciosamen-

210 te el procedimiento aplicable a la práctica de las pruebas pertinentes. 
En un estudio pormenorizado cabría señalar que por mor de los artículos 12.2 LSV y 22.1 RLSV los agentes encargados de la vigilancia del tráfico practicarán las pruebas que reglamentariamente se establezcan para detectar la posible intoxicación alcohólica, que consistirán normalmente en la verificación del aire expirado mediante alcoholímetros oficialmente autorizados al objeto de lograr una determinación cuantitativa del grado de impregnación alcohólica concurrente en el sujeto requerido. Dichas pruebas podrán reiterarse a efectos de contraste, ya sea a petición del interesado ya sea por orden de la Autoridad Judicial, y en este caso pueden consistir en análisis de sangre, orina u otros análogos.

En los supuestos en que quienes se sometieren a las pruebas sufrieran cualesquiera dolencias o enfermedades de gravedad tal que impidan la práctica de aquéllas las que se les hayan de realizar vendrán determinadas por el personal facultativo del centro médico al que hubieren sido evacuados, tal como resulta del artículo 22.2 RLSV. Esta previsión tiene su fundamento en la realidad objetiva referida a diversas apreciaciones constatadas que pueden versar sobre la existencia de supuestos de anormalidad bien traducidos en enfermedades respiratorias que pudieran impedir la práctica de la prueba o que de practicarse mermaría las garantías legales, bien derivados de la apreciación in situ de evidentes padecimientos que pudieran distorsionar las conclusiones arrojadas, bien por resultar acreditada la ingesta de medicamentos que por su composición pudieran alterar significativamente el resultado de su práctica. Todo lo cual, no obsta, a la distinción de las situaciones señaladas de otras pretendidas o forzadas situaciones que la casuística permite observar y cuyo objeto no es otro que la oposición a someterse a tal prueba.

Con todo, se trata de preservar las garantías legales aplicables así como evitar que al socaire de cualesquiera lagunas en esta materia se pudieran eludir las posibles responsabilidades y, es que la norma general para la realización de las pruebas de alcoholemia no es la de practicar, de entre las posibles, la que el requerido elija o elijan los agentes, sino la de expirar a través del aparato medidor y, sólo en los supuestos indubitados de anormalidad como los precitados podrán practicarse otro tipo de pruebas.

Si el resultado de la prueba practicada fuera positivo o sin superar los límites concurrieran síntomas evidentes de hallarse bajo la influencia de bebidas alcohólicas, el agente a los efectos de una mayor garantía y de contraste, practicará una segunda prueba de detección alcohólica también por el sistema de aire espirado, artículo 23 RLSV, y es en este momento cuando conviene precisar que el interesado está asistido de una serie de derechos, a saber:

a. A ser informado de modo previo de la práctica de esa segunda prueba con el etilómetro.

b. A controlar, por si mismo o por cualquiera de sus acompañantes o testigos presentes, que entre la realización de la primera y de la segunda prueba medie un tiempo mínimo de 10 minutos. 
c. A formular las alegaciones u observaciones que estime conveniente, por sí o por su acompañante o defensor, en su caso, las cuales se consignarán por diligencia.

d. A contrastar los resultados obtenidos mediante análisis de sangre, orina u otros análogos, que el personal facultativo del centro médico al que sea trasladado estime más adecuados, cuyo importe será a su cargo si el resultado fuera positivo y a cargo de los órganos periféricos de la Jefatura Central de Tráfico o de las autoridades municipales o autonómicas competentes cuando sea negativo.

Íntimamente relacionado con las consecuencias de los resultados arrojados se encuentra la medida de inmovilización del vehículo cuyos gastos serán sufragados por el conductor. Su llevanza a la práctica, desarrollada en el artículo 25 RLSV, procede no sólo en el supuesto ya citado de negativa a efectuar las pruebas pertinentes sino también cuando no habiendo ninguna otra persona debidamente habilitada para hacerse cargo de la conducción del vehículo, el resultado de las pruebas y de los análisis, en su caso, fuere positivo.

En el marco procedimental propiamente dicho, en los expedientes administrativos que se instruyen en esta materia, se ha venido planteando reiteradamente la validez o no de los aparatos medidores y se ha resuelto de modo primordial la validez del certificado de verificación periódica del instrumento utilizado al objeto de acreditar la conformidad del mismo para su función y contenido, siendo trasladable a esta materia la jurisprudencia emanada acerca de los cinemómetros, en el sentido de entender que es la superación de los distintos controles a los que el aparato medidor ha de ser sometido la que garantiza su fiabilidad.

No obstante, en el ámbito instructor del proceso penal nos incumbe ahora significar la existencia, además del ya estudiado test de alcoholemia, de otros elementos de prueba dirigidos al mismo fin determinador del tipo, así se conforman otras tales como la declaración del acusado y de los testigos que normalmente son agentes policiales, la diligencia de apreciación de signos externos y las circunstancias y modo de la conducción - SAP de Madrid, Sección 17. a , número 776/2005, de 12 de julio y SAP de Burgos, Sección 1. a , número 234/2004, de 30 de diciembre-.

Abordamos ahora las dos últimas, dado que las primeras ya han sido objeto de nuestra atención.

En primer lugar la diligencia de síntomas psico-físicos levantada por los agentes policiales cuyo testimonio claro y preciso a presencia judicial puede llevar a la Sala a determinadas conclusiones acerca del injusto. La STC 137/2005, de 23 de mayo, considera suficientemente garante la actividad probatoria que acredita el elemento subjetivo del tipo, esto es, la afectación o influencia de la ingesta de alcohol en las facultades psicofísicas del conductor del vehículo, a partir de los signos externos apreciados 212 juicio. 
A este respecto la jurisprudencia distingue entre los síntomas denominados equívocos e inequívocos. A los primeros los configura como accidentales, en cuanto imprecisos o confusos al entender que pueden irrumpir con o sin la influencia del alcohol y, cita como tales el aspecto externo apático, con abatimiento o cansancio, los ojos apagados, la dificultad de fijación de la mirada, el comportamiento insultante, agresivo o irrespetuoso. A los segundos los diseña como señales evidentes de una sintomatología patente de la inmoderada ingesta alcohólica y reputa como ejemplos de ellas el habla pastosa, la repetición de frases o ideas en elevado tono de voz con expresiones embrolladas o carentes de coherencia y de toda conexión léxica lógica y, la deambulación con movimientos oscilantes. No resulta valadí la distinción expresada en el medida en que cuando concurran exclusivamente como prueba de cargo los datos de sintomatología equívoca, la posibilidad de condena queda limitada dado que la duda ha de favorecer al reo-SAP $3 .^{\text {a }}$ de Girona n. ${ }^{\circ}$ 658/2002, de 8 de octubre-. A este principio le dedicaremos unas líneas más adelante al exponer las garantías del artículo 24.2 CE.

$\mathrm{Y}$, en segundo lugar, es digno de observación el dato alusivo al modo y circunstancias de la conducción, siendo determinantes las declaraciones en este sentido al poder ser entendidas como acreditativas no sólo de la influencia alcohólica sobre la conducción, sino también, y en su caso, del grave peligro que para otros vehículos y demás usuarios de la vía supuso dicha conducción anormal e irregular.

Respecto de la aplicación en los casos de alcoholemia de las garantías del artículo 24.2 CE la STC 2/2003 ha vuelto a dar respuesta a esta intrincada cuestión (FJ 10):

"En cuanto a las modulaciones con las que se proyecta el derecho al proceso con todas las garantías se han de resaltar las relativas a la garantía de imparcialidad, pues ésta no puede predicarse de la Administración sancionadora en el mismo sentido que respecto de los órganos judiciales -especialmente en las infracciones de autoprotección-, ni impone las mismas reglas a la actuación de la Administración (SSTC 22/1990, de 15 de febrero, FJ 4; 14/1999, de 22 de febrero, FJ 4).

En relación con el derecho a la presunción de inocencia (art. 24.2 CE), si bien hemos declarado que en el ámbito del procedimiento administrativo sancionador rige este derecho sin restricciones (por todas SSTC 170/1990, de 5 de noviembre, FJ 4; 212/1990, de 20 de diciembre, FJ 5), no puede desconocerse que hemos negado la extensión del derecho a la publicidad del proceso al ámbito del procedimiento administrativo sancionador (STC 2/1987, de 21 de enero, FJ 6) y que hemos admitido la validez como prueba de cargo de los partes de inspección (STC 170/1990, de 5 de noviembre, FJ 4) o de los informes obrantes en autos (SSTC 212/1990, de 20 de diciembre, FJ 5; 341/1993, de 18 de noviembre, FJ 11), con independencia de que carezcan de presunción de veracidad (STC 76/1990, de 26 de abril, FJ 8). La admisión de la validez de estas pruebas, en conexión con la inexistencia de la garantía de publicidad en el procedimiento administrativo sancionador, implica que en éste no se proyecta una de las garantías esenciales del derecho al proceso justo y a la presunción de inocencia en el ámbito penal (por todas STC 167/2002, de 18 de septiembre), esto es, que la valoración de la prueba ha de efectuarse en condiciones de oralidad, publicidad e inmediación y que la declaración de responsabilidad penal y la imposi- 
ción de una sanción de este carácter sólo puede sustentarse en pruebas valoradas en dichas condiciones.

Estas diferencias, que no empañan la legitimidad constitucional del ejercicio de la potestad sancionadora de la Administración, sin embargo, determinan que, en caso de dualidad de ejercicio de la potestad sancionadora del Estado, por la Administración y la jurisdicción penal, las resoluciones dictadas en ésta no puedan ceder ante las dictadas en aquélla.

De ello deriva que ni siquiera la determinación fáctica realizada en el procedimiento administrativo sancionador pueda considerarse que ha sido objeto de pronunciamiento definitivo en estos casos de concurrencia de infracciones administrativa y penal, pues dicha acotación jurídica de los hechos ha tenido lugar por un órgano público del que no puede predicarse la imparcialidad en el mismo sentido en que se predica y exige de los órganos judiciales y sin sujeción a las garantías de inmediación, oralidad y publicidad en la valoración de la prueba.

Por ello, si, en el caso origen de la demanda de amparo, la ingestión de alcohol pudo considerarse acreditada en el procedimiento administrativo a través del anexo documental del atestado policial, ello no es suficiente para considerar este hecho válidamente acreditado en el proceso penal, pues en éste se requiere la ratificación en el juicio oral del atestado y de los resultados de las pruebas de alcoholemia por los agentes que lo realizaron (por todas, STC 188/2002, de 14 de octubre).

Por lo demás, a esta solución no se opone el alcance del derecho reconocido en el art. 4 del Protocolo 7 CEDH, pues el Tribunal Europeo de Derechos Humanos en su Sentencia de 29 de mayo de 2001, caso Franz Fischer c. Austria ( $\$ 31$ ) ha sostenido que los Estados parte del Convenio europeo de derechos humanos conservan libertad para "regular cuál de las dos infracciones ha de ser perseguida".

En cuanto al valor probatorio del atestado policial -Sentencia de la Audiencia Provincial de Alicante, Sección 2. a, número 521/2006, de 11 de octubre y Sentencia de la Audiencia Provincial de La Rioja, Sección única, número 75/2003, de 29 de abril-. Para desvirtuar la presunción de inocencia se exige una actividad probatoria de cargo suficiente que ha de realizarse normalmente en el acto del juicio oral. El atestado policial, de conformidad con lo dispuesto en el artículo 297 de la Ley de Enjuiciamiento Criminal y con la doctrina del Tribunal Constitucional únicamente tiene el valor genérico de denuncia, por lo que no se erige en medio sino en objeto de prueba, pudiendo ser introducido al juicio oral a través de auténticos medios probatorios tales como la declaración testifical del funcionario de policía que intervino en el atestado ratificando el contenido de aquél - SSTC 47/1986, 80/1986, 161/1990, 80/1991, 303/1993que al tratarse de manifestación efectuadas por persona imparcial investida de pleno valor probatorio a tenor de los artículos 297 y 717 de la LECR, conforma prueba de cargo apta para desvirtuar la presunción de inocencia reconocida al acusado ${ }^{15}$.

15 Con carácter general, Casino Rubio (2008), passim. Sobre la prueba en este tipo de infracciones,
214 Climent Durán, C. (2007); Díaz Revorio, F. J.(2000), p. 142 y ss; aunque algo antiguo, posee ideas aún valiosas, 
En lo atinente a la probatio del test de alcoholemia desde los años 80 la jurisprudencia constitucional, ya reflejada, lo ha considerado como prueba preconstituida o anticipada - SSTC de 13 de octubre de 1992 y de 9 de mayo de 1988- , y ha venido entendiendo que preconstituye una prueba a la que puede asignarse, lato sensu, el carácter de prueba pericial; por tanto, siempre que se haya llevado a cabo con todas las garantías necesarias su carácter obliga a reconocerle alcance probatorio y, estas garantías son: las formales al objeto de preservar el derecho de defensa, en especial la oportuna información que confiera al interesado el conocimiento de su derecho a un segundo examen alcoholimétrico y a la práctica médica de un análisis de sangre; y, el acceso al proceso en condiciones que permitan respetar los principios de inmediación, oralidad y contradicción y confieran al juzgador la facultad de examinar por sí mismo las circunstancias que determinaron su práctica, singularmente a través de la ratificación o declaración complementaria de quienes la llevaron a cabo o, de la práctica de otras pruebas tendentes a acreditar la influencia de la bebida alcohólica en la conducción. -SAP de La Rioja, Sección única, número 98/2003, de 5 de junio y SAP de Málaga, Sección 3. ${ }^{a}$, número 361/2001, de 20 de diciembre-.

\section{UN BREVE EXCURSUS: ¿POR QUÉ LLAMAMOS “COLABORAR" A LO QUE SIMPLEMENTE ES “OBEDECER”?}

Concluimos con una breve reflexión con otro de los aspectos desconcertantes de esta materia. Existe una clara y mayoritaria tendencia a referirse a los deberes de sometimiento de los artículos 12.2, en relación con el 65.5 b), LSV y 21 RLSV, y el artículo 383 CP, como "deberes de colaboración", en lo que ahora interesa, con la Administración Pública, y en este caso, con los agentes de la autoridad que nos someten a la práctica de una alcoholemia. Y nuestra pregunta es por qué llamamos colaborar a lo que, a todas luces, es un supuesto de sujeción a las órdenes de la autoridad competente.

Cierto que de esta manera se concreta, tanto en lo penal como en lo administrativo, el tipo genérico de desobediencia del artículo 556 CP. Pero no es menos cierto que la conducta sancionada no es en rigor una negativa a "colaborar" con la autoridad pública, sino la desobediencia a una de sus órdenes. En definitiva, se sanciona por la infracción del deber de sometimiento a las normas que regulan una actividad intervenida; no el que no se presta la persona a ayudar a la Administración en una de sus actividades. El TC lo dijo con claridad en la STC 107/1985 FJ 3. :

En estos términos, la verificación de la prueba que se considera supone, para el afectado, un sometimiento, no ilegítimo desde la perspectiva constitucional, a las normas de policía, sometimiento al que, incluso, puede verse obligado sin la previa existencia de indicios de infracción, en el curso de controles preventivos.

Serrano Hoyo, G. (1993), passim; Sobre el valor probatorio de los atestados policiales: Planchadell Gargallo, A. (2008), p. 379 y ss; Rodríguez Ramos, L. (1997), p.2 y ss; Soriano Soriano, J. R. (2000), passim. 
Lo que reiteró la STC 161/1997 (FJ $4 .^{\circ}$ ) justo al ocuparse del delito de negativa a someterse a las alcoholemias:

\begin{abstract}
"En estos términos, la verificación de la prueba que se considera supone, para el afectado, un sometimiento, no ilegítimo desde la perspectiva constitucional, a las normas de policía, sometimiento al que, incluso, puede verse obligado sin la previa existencia de indicios de infracción, en el curso de controles preventivos realizados por los encargados de velar por la regularidad y seguridad del tránsito" (fundamento jurídico 3.; también, SSTC 22/1988, fundamento jurídico 1., y 252/1994, fundamento jurídico 4.) (negrita de los autores).
\end{abstract}

Poco más puede decirse. Pero es que, tiene relevancia hablar de "colaboración". Llamarlo así tiene consecuencias para la pretensión de sancionar su infracción. En primer lugar, la colaboración implicaría la disposición activa de la persona para ayudar a otra en una determinada acción o para un fin específico; en segundo lugar, negarse a colaborar siempre será menos grave que negarse a obedecer una orden de la autoridad competente, por lo que la "pena por no colaborar" no resistiría un juicio de proporcionalidad sensato; $y$ en tercer lugar, castigar la negativa a "colaborar" nada tiene que ver con la conducta que realmente se persigue, por lo que, desde la perspectiva administrativa, esa desconexión impediría extraer consecuencia alguna de la no colaboración, en fin, no cabría presumir que la negativa a colaborar esconde la infracción de conducir bajo los efectos del alcohol.

Pero es que ni siquiera la literalidad de los preceptos avala semejante y engañosa terminología. Llamemos a las cosas por su nombre, y cuando se trata de obedecer a la autoridad, no se trata de colaborar con ella.

\title{
BIBLIOGRAFÍA
}

Casino Rubio, M (2008), "Las garantías constitucionales del procedimiento administrativo sancionador", en La potestad sancionadora de la agencia española de Protección de Datos, AAVV, Thomson/Civitas/AEPD, Cizur Menor/Madrid, 2008.

1(2010), "El valor probatorio del silencio del inculpado y el principio de presunción de inocencia en las infracciones de tráfico" (original inédito cedido por el autor)..

2(2010), La increible historia del deber de identificar al conductor infractor, Civitas/ Thomson, Cizur Menor (Navarra), 2010.

Climent Durán, C. (2007), "La prueba en los delitos contra la seguridad del tráfico (medición del grado de alcoholemia)", Estudios de Derecho Judicial, N. ${ }^{\circ} 114,2007$, pp. 359-384.

Comas de Argemir Cendra, M (1998), "La negativa del imputado a la práctica de una diligencia de investigación: La prueba de alcoholemia", Cuadernos de Derecho judicial, N. ${ }^{\circ} 3,1998$, pp.63-112.

Cuenca Sánchez, J. C. (2007), "El proyecto de reforma del Código penal en la fijación 216 de una tasa de alcoholemia presuntiva de la influencia del alcohol en la conduc- 
ción ¿problemas de constitucionalidad?", La Ley: Revista jurídica española de doctrina, jurisprudencia y bibliografía, N. ${ }^{\circ}$ 1, 2007, pp. 1502-1506.

Cuesta Pastor, P. J. (1999), "La criminalización de la negativa a someterse al test de alcoholemia del artículo 380 del Código Penal”, Tráfico y Seguridad Vial, N. ${ }^{\circ} 11$, 1999, pp. 4-14.

(1998), "Comentario a la sentencia del Tribunal Constitucional 161/1997 de 2 de octubre: (la constitucionalidad del artículo 380 del Código Penal: criminalización de la negativa al test de alcoholemia)", Revista General de Derecho, N. ${ }^{\circ} 642,1998, \mathrm{pp}$. $1933-1948$.

(2000), "Comentario a la sentencia del Tribunal Supremo 3/1999, acerca de la criminalización de la negativa a someterse al test de alcoholemia: Repercusiones en cuanto al principio de seguridad jurídica", La Ley, N. ${ }^{2}$ 2, 2000, pp. 1505-1509.

Díaz Revorio, F. J. (2000), "La prueba de alcoholemia y sus consecuencias en los ámbitos administrativo-sancionador y penal: el análisis desde la perspectiva constitucional", Parlamento y Constitución. Anuario, N. ${ }^{\circ}$ 4, 2000, pp. 121-168.

Fernández Bautista, S. (2007) "El delito de negativa a la realización de las pruebas de alcoholemia (art. 383 CP)", Diario La Ley, N. ${ }^{\circ} 6841,2007$.

Fernández Bautista, S. (2008) "El delito de negativa a la realización de las pruebas de alcoholemia (art. 383 CP)”, Tráfico y Seguridad Vial, N. ${ }^{\circ}$ 109, 2008, pp. 37-50; también en Seguridad vial y derecho penal: análisis de la LO 15/2007, que modifica el Código penal en materia de seguridad vial, coord. Mir Puig, Corcoy Bidasolo, Cardenal Montraveta, 2008, pp. 179-206.

Francisco López, A. de (1993), "La negativa al sometimiento a la prueba de alcoholemia como delito de desobediencia grave”, Escritos jurídicos en memoria de Luis Mateo Rodríguez, Vol. 1, 1993, pp. 207-218.

Ganzenmüller Roig, C., Frigola Vallina, J., Escudero Moratalla, J. F. (1997), “El nuevo delito de negativa a someterse a las pruebas de alcoholemia, considerado como desobediencia grave a la autoridad", Cuadernos de política criminal, N. ${ }^{\circ}$ 61, 1997, pp. 69-91.

Guerrero Fernández, P. (2000), "La negativa a someterse a las pruebas de alcoholemia”, luris: Actualidad y práctica del Derecho, N. ${ }^{\circ} 36,2000$, pp. 46-54.

José Falcón, M., (2006) “Finalidad de la sanción tras negativa a realizar una prueba de alcoholemia: STC 161/1997, de 2 de octubre”, Persona y Derecho: Revista de fundamentación de las Instituciones Jurídicas y de Derechos Humanos, N. ${ }^{\circ}$ 55, 2006 , pp. 771-792.

Lorente Hurtado, F. (1986), “La prueba de alcoholemia en la jurisprudencia constitucional”, Poder Judicial, N. ${ }^{\circ} 1,1986$, pp. 59-70.

Marín de Espinosa Ceballos, E. B. (2000), “La negativa a someterse al control de alcoholemia: delimitación entre el ilícito administrativo y el ilícito penal. A propósito de la sentencia del TS de 9 de diciembre de 1999", Tráfico y Seguridad Vial, N. ${ }^{\circ} 15$, 2000, pp. 4-11.

Martínez Ruiz, J. (2002), "La negativa a la prueba de alcoholemia: el artículo 380 del Código Penal (Visicitudes jurisprudenciales de un delito poco afortunado: el artículo 380 del (P de 1995)", Revista de Derecho Penal, N. ${ }^{\circ}$ 7, 2002, pp. 71-100. 
Miró Llinares, F. (2003), “La interpretación del delito de negativa al sometimiento de la prueba de alcoholemia tras la sentencia del Tribunal Supremo de 22 de marzo de 2002", Actualidad penal, N. ${ }^{\circ}$ 1, 2003, pp. 65-91.

(2003), "Negativa al sometimiento de la prueba de alcoholemia. Posiciones doctrinales y pronunciamientos jurisprudenciales", Revista jurídica de la Comunidad Valenciana, N. ${ }^{\circ} 8,2003$, pp. 85-128.

Muñoz Cuesta, J. (2009),"Delito de negativa a someterse a las pruebas de alcoholemia y detección de drogas: problemas que suscita la interpretación del art. 383 CP", Revista Aranzadi Doctrinal, N. ${ }^{\circ}$ 2, 2009, pp. 7-17.

Nieto, A. (2002), Derecho Administrativo Sancionador, Tecnos, Madrid.

Pérez Manzano, M (2003), "Reflexiones sobre el derecho fundamental a no padecer bis in idem al hilo de la STC 2/2003, de 16 de enero", La Ley, N. ${ }^{\circ} 3,2003$, pp.1652 y ss.

Pérez-Cruz Martín, A. J. (1992), "La prueba de alcoholemia en el nuevo Reglamento General de Circulación”, La Ley, N. ${ }^{\circ}$ 3, 1992, pp. 1069-1073.

Planchadell Gargallo, A. (2008), "Valor probatorio del atestado policial”, en Seguridad vial: (especial referencia a la reforma operada en el Código Penal mediante la Ley Orgánica 15/2007, de 30 de noviembre), coord. por Vidales Rodríguez y Mera Redondo, 2008, pp. 379-400.

Pulido Quecedo, M. (2007), "Derecho a la intimidad, consentimiento informado y pruebas de alcoholemia", Repertorio Aranzadi del Tribunal Constitucional, N. ${ }^{\circ} 14$, 2007, pp. 9-11.

Rodríguez Ramos, L. (1997), “¿Atestado, pericia o cuestión prejudicial? (Sobre ciertas corruptelas en la tramitación de causas por injustos administrativos criminal)", Actualidad jurídica Aranzadi, N. ${ }^{\circ}$ 310, 1997, pp. 1.

Sarrato Martínez, L. (2009), "La negativa a someterse a las pruebas de alcoholemia: al límite entre la infracción penal y la infracción administrativa”, Diario La Ley, N. ${ }^{\circ}$ 7162, 2009.

Serrano Hoyo, G. (1993), “La nueva regulación de las pruebas de alcoholemia: Su valor probatorio en la jurisprudencia constitucional”, La Ley, N. ${ }^{\circ}$ 2, 1993, pp. 862-874.

Soriano Soriano, J. R. (2000), "Eficacia probatoria del atestado de tráfico: su valoración en el juicio oral”, Revista jurídica de Catalunya, Vol. 99, N. 1, 2000, pp. 163 172.

Vaamonde Fernández, J. M. (1997), “Conducción bajo la influencia de bebidas alcohólicas: la prueba de la alcoholemia”, La Ley, N. ${ }^{\circ}$ 3, 1997, pp. 1917-1923.

Valencia Martín, G.(2000), “Derecho Administrativo Sancionador y Principio de legalidad”, en El principio de legalidad. Actas de las V Jornadas de la asociación de Letrados del Tribunal Constitucional, CECP, TC, Madrid, p.77 y ss.

Varona Gómez, D. (2000), “El delito de negativa a las pruebas de alcoholemia tras las sentencias 161/1997 y 234/1997 del Tribuna Constitucional y la sentencia del Tribunal Supremo (sala 2..$^{\text {) }}$ de 9 de diciembre de 1999", La Ley, N. ${ }^{\circ} 1,2000$, pp. 15851598.

Recibido: 20 de mayo de 2010 